\title{
Comparative Evaluation of 4 and 6-Carbon Spacer Conformationally- Flexible Tetrahydroisoquinolinyl Benzamide Analogues for Imaging the Sigma-2 Receptor Status of Solid Tumors
}

\author{
Iljung Lee, Brian P. Lieberman, Shihong Li, Catherine Hou, \\ Mehran Makvandi, Robert H. Mach* \\ Department of Radiology/Nuclear Medicine, Perelman School of Medicine, \\ University of Pennsylvania, Philadelphia, Pennsylvania 19014, USA
}

Submitted to: Nuclear Medicine and Biology

*Corresponding Authors:

Robert H. Mach, PhD

Tel: +1-215-746-8233

Fax: +1-215-746-0002

Email: $\underline{\text { rmach@mail.med.upenn.edu }}$ 


\begin{abstract}
Introduction: Nine novel analogues were synthesized including a 6-carbon spacer analogue of ISO-1 (7). They have moderate binding affinity for sigma-2 $\left(\sigma_{2}\right)$ receptors and high selectivity for $\sigma_{2}$ receptors relative to sigma-1 $\left(\sigma_{1}\right)$ receptors.

Methods: $\left(\left[{ }^{18} \mathrm{~F}\right] 7\right)$ was synthesized and evaluated as a candidate ligand for positron emission (PET) imaging of the $\sigma_{2}$ receptor in tumors. Radioligand $\left[{ }^{18} \mathrm{~F}\right] 7$ was radiolabeled with ${ }^{18} \mathrm{~F}$ via displacement of the corresponding mesylate precursor with $\left[{ }^{18} \mathrm{~F}\right]$ fluoride. Cellular uptake study of $\left[{ }^{18} \mathrm{~F}\right] 7$ was performed in EMT-6 tumor cell and in vivo biodistribution study of $\left[{ }^{18} \mathrm{~F}\right] 7$ carried out in female Balb/c mice bearing EMT-6 tumors.

Results: $\left[{ }^{18} \mathrm{~F}\right] 7$ had a respectable tumor uptake $(1.55 \% \mathrm{ID} / \mathrm{g}$ at $60 \mathrm{~min}$ post-injection) and high tumor/muscle ratios at 60 and 120 min post-injection. MicroPET imaging of $\left[{ }^{18} \mathrm{~F}\right] 7$ in tumorbearing mice as above showed significant tumor localization and a high tumor/muscle ratio as well.
\end{abstract}

Conclusions: These results are similar to or better than $\left[{ }^{18} \mathrm{~F}\right] \mathbf{I S O}-\mathbf{1}\left(\left[{ }^{18} \mathrm{~F}\right] \mathbf{3}\right)$, which indicates that $\left[{ }^{18} \mathrm{~F}\right] 7$ has potential for imaging the $\sigma_{2}$ receptor status of solid tumors.

Keywords: PET, sigma-2 receptors, tumor imaging, tumor cell proliferation, EMT-6 cells 


\section{Introduction}

Sigma $(\sigma)$ receptors represent a class of proteins that were initially thought to be a type of opioid receptor [1]. It has been established that $\sigma$ receptors are a distinct class of receptors, largely based on in vitro binding and behavioral pharmacology studies [2].

$\sigma$ receptors are present in many normal tissues including liver, kidney, endocrine glands, and the central nervous system (CNS) [3]. Two subtypes have been pharmacologically established as $\sigma_{1}$ and $\sigma_{2}$ receptors $[4,5]$. The $\sigma_{1}$ receptor has been cloned from tissues of guinea pig, rat, mouse, and man [6], and the crystal structure of the protein reveals a trimeric architecture consisting of a single trans-membrane domain in each protomer [7]. The $\sigma_{2}$ receptor has not been cloned yet, but our group has reported that the putative $\sigma_{2}$ receptor binding site resides within the PGRMC1 (progesterone receptor membrane component 1) protein complex [8]. However, recent studies using stable cell lines where the PGRMC1 had been knocked out using either a shRNA or CRISPR vector for the PGRMC1 have shown that there is no decrease in binding of $\left[{ }^{3} \mathrm{H}\right] \mathrm{DTG}$ binding in PGRMC1 knockout cells $[9,10]$. These data indicate that the DTG-sensitive $\sigma_{2}$ receptor binding site is not located within the amino acid sequence of the PGRMC1, and supports the need for further studies in the identification of the $\sigma_{2}$ receptor.

Although the molecular identity of the receptor is subject to debate, it is known that $\sigma_{2}$ receptors are overexpressed in a wide variety of human and murine tumor cell lines and solid tumors such as breast adenocarcinoma, neuroblastoma, leukemia, glioblastoma, lung carcinomas, renal carcinoma, colon carcinoma, sarcoma, urinary bladder tumor, pancreatic cancer, and prostate cancer [11-24]. The density of $\sigma_{2}$ receptors has been reported to be more abundant than $\sigma_{1}$ receptors in a wide panel of tumor cells grown under cell culture conditions [12]. In addition, 
the density of $\sigma_{2}$ receptors is found to be 8-10 fold higher in proliferating $v s$. quiescent mouse mammary adenocarcinoma cells both in vitro [24] and in vivo [23]. This correlation between $\sigma_{2}$ receptor density and the proliferative status of tumor cells has been reported to be independent of other factors, biological or physiological, such as species, cell types, ploidy, cell-cell contact, nutrient depletion, low pH, altered metabolic states, or tumor size [23, 24]. Our group has also reported the localization of $\sigma_{2}$ receptors in the mitochondria, lysosomes, endoplasmic reticulum, and plasma membrane of breast cancer cells using two-photon and confocal microscopy probes $[25]$.

In addition to being an excellent biomarker of cell proliferation for imaging studies, the $\sigma_{2}$ receptor has also proven to be a promising target for as either a monotherapy for treating cancer, or as a mechanism for delivering a therapeutic cargo to cancer cells [11, 22, 26-29]. Therefore, radiolabeled $\sigma_{2}$ receptor ligands can be used to assess the proliferative status of solid tumors with positron emission tomography (PET) and single photon emission computed tomography (SPECT), as well as serving as a companion diagnostic for identifying tumors that would respond to $\sigma_{2}$ receptor targeting therapeutics [29-33].

Our group has previously radiolabeled several $\sigma_{2}$ receptor ligands having a high affinity for $\sigma_{2}$ receptors and excellent $\sigma_{2}: \sigma_{1}$ selectivity ratios as potential PET tracers for clinical research studies. The initial in vitro and in vivo evaluation of these radiotracers has been reported previously [34-37]. The 6,7-dimethoxy-1,2,3,4-tetrahydroisoquinoline moiety is an optimal structure to increase binding affinity and selectivity for $\sigma_{2}$ receptors [36, 38-40]. Among these compounds, ${ }^{11} \mathrm{C}$-radiolabeled benzamide analogues have high binding affinity and selectivity for $\sigma_{2}$ receptors (Figure 1), and a good relationship between tumor uptake and lipophilicity of those compounds has been shown.[38] Although ${ }^{11} \mathrm{C}$-labeled benzamide analogues have a high 
potential for PET imaging of $\sigma_{2}$ receptors (compounds $\mathbf{1}$ and $\mathbf{2}$, Figure 1), we also developed ${ }^{18} \mathrm{~F}$ labeled benzamide analogues (compounds 3 and 4, Figure 1) due to the short half-life of ${ }^{11} \mathrm{C}$ (20.4 min) [36]. Recently, the first human imaging studies of the $\sigma_{2}$ receptor ligand $\left[{ }^{18} \mathrm{~F}\right] \mathbf{I S O}-\mathbf{1}$ $\left(\left[{ }^{18} \mathrm{~F}\right] \mathbf{3}\right)$ were accomplished and demonstrated the potential utility of this compound in imaging the proliferative status of solid tumors [41]. However, it has been reported that 1,2,3,4tetrahydroisoquinoline with the flexible 6-carbon spacer, and benzofuran ring as the benzamide moiety (5, Figure 1) has higher binding affinities and selectivity for $\sigma_{2}$ receptors than the 4 and 5 carbon spacer group, and the authors also suggested that the corresponding indole and benzothiophene analogs should have improved binding affinities and selectivity for $\sigma_{2}$ receptors [40].

In this study, we further explored this structural optimization strategy by increasing the carbon spacer length from four to six carbons for hydrophobic spacer, and replaced the benzamide ring with either an indole or benzothiophene ring (Figure 2). We also synthesized the 6-carbon spacer analogue of ISO-1 and evaluated the compounds for their in vitro binding properties to the $\sigma$ receptors. The in vivo properties of $\left[{ }^{18} \mathrm{~F}\right] \mathbf{I S O}-\mathbf{1}$ (4-carbon spacer) $\left(\left[{ }^{18} \mathrm{~F}\right] \mathbf{3}\right)$, a well-established $\sigma_{2}$ radioligand, and $\left[{ }^{18} \mathrm{~F}\right] \mathbf{7}$, the corresponding $\left[{ }^{18} \mathrm{~F}\right]$-labeled 6-carbon spacer analogue of ISO-1, were also compared.

\section{Materials and Methods}

\subsection{Reagents and Equipment}

Chemicals were purchased from Sigma-Aldrich (St. Louis, MO, USA) and Alfa Aesar (Ward 
Hill, MA, USA). ${ }^{1} \mathrm{H}$ NMR spectra were obtained using a Bruker DMX 360 (360 MHz) spectrometer (Rheinstetten, Germany), and chemical shifts ( $\delta$ ) were reported as the ppm downfield of the internal tetramethylsilane. LCMS (Liquid Chromatography Mass Spectroscopy) and HRMS (High Resolution Mass Spectroscopy) were obtained using a Waters microMass zQ and LCT Premier XE LC/MS system (Waters Corporations, Milford, MA, USA). For purification and analysis of radioligands, HPLC analysis was conducted using the Agilent 1100 (Agilent Technologies, Santa Clara, CA, USA) equipped with a semi-preparative column (Agilent SB-C18, $5 \mu \mathrm{m}, 9.4$ x $100 \mathrm{~mm}$ ) or Waters Alliance e2695 HPLC (Waters Corporations, Milford, MA, USA) equipped with an analytical column (Agilent ZORBAX Eclipse XDB-C18, $5 \mu \mathrm{m}, 4.6 \times 150 \mathrm{~mm})$. The eluent was monitored simultaneously using UV (281 nm) and NaI(T1) radioactivity detectors. TLC was performed on Merck $\mathrm{F}_{254}$ silica plates and analyzed on a Bioscan Mini-Scan TLC Imaging Scanner (Hopkinson, MA, USA).

$\left[{ }^{18} \mathrm{~F}\right]$ Fluoride was produced by the ${ }^{18} \mathrm{O}(\mathrm{p}, \mathrm{n}){ }^{18} \mathrm{~F}$ reaction using an IBA Cyclone ${ }^{\circledR} 18$ (Louvainla-Neuve, Belgium) or JSW (Tokyo, Japan). Radioactivity was measured in a dose calibrator (Capintec, Ramsey, NJ, USA). Binding studies were performed using a Unifilter 96 harvester (Perkin Elmer, Boston, MA), and bound radioactivity was counted on a Microbeta $^{2}$ liquid scintillation counter (Perkin Elmer, Boston, MA) with a counting efficiency of $\sim 45 \%$. All animal experiments were performed under IACUC-approved protocols in compliance with the guidelines for the care and use of research animals established by the University of Pennsylvania.

\subsection{Synthesis}


and 2-(6-(6,7-dimethoxy-3,4-dihydroisoquinolin-2(1H)-yl)hexyl)isoindoline-1,3-dione (10b)

10a and 10b were synthesized using a modification of the reported method [42, 43]. 2-(4bromobutyl)isoindoline-1,3-dione (or 2-(6-bromohexyl)isoindoline-1,3-dione) (15.7 mmol) was added to a solution of 6,7-dimethoxy-1,2,3,4-tetrahydroisoquinoline hydrochloride (13.1 mmol) and $\mathrm{K}_{2} \mathrm{CO}_{3}(5.40 \mathrm{~g}, 39.2 \mathrm{mmol})$ in $\mathrm{CH}_{3} \mathrm{CN}(37.5 \mathrm{~mL})$, and the mixture stirred at reflux for $20 \mathrm{~h}$. The reaction mixture was cooled to ambient temperature, the $\mathrm{CH}_{3} \mathrm{CN}$ removed in vacuo, and $\mathrm{H}_{2} \mathrm{O}(50 \mathrm{~mL})$ was added. The mixture was extracted with EtOAc $(2 \times 50.0 \mathrm{~mL})$, the combined organic layer was washed with brine $(50.0 \mathrm{~mL})$, dried over anhydrous $\mathrm{Na}_{2} \mathrm{SO}_{4}$ and concentrated under reduced pressure.

Flash column chromatography (15:1 $\left.\mathrm{CH}_{2} \mathrm{Cl}_{2}-\mathrm{MeOH}\right)$ afforded compound $\mathbf{1 0 a}(3.87 \mathrm{~g}, 75 \%)$ as a pale yellow solid. mp 109.3-109.5 ${ }^{\circ} \mathrm{C} .{ }^{1} \mathrm{H}$ NMR $\left(\mathrm{CDCl}_{3}\right) \delta 7.77(\mathrm{dq}, J=39.6$ and $3.60 \mathrm{~Hz}$, 4H), $6.58(\mathrm{~s}, 1 \mathrm{H}), 6.51(\mathrm{~s}, 1 \mathrm{H}), 3.83(\mathrm{~s}, 3 \mathrm{H}), 3.82(\mathrm{~s}, 3 \mathrm{H}), 3.74(\mathrm{t}, J=7.20 \mathrm{~Hz}, 2 \mathrm{H}), 3.54(\mathrm{~s}, 2 \mathrm{H})$, $2.81(\mathrm{t}, J=5.75 \mathrm{~Hz}, 2 \mathrm{H}), 2.70(\mathrm{t}, J=5.40 \mathrm{~Hz}, 2 \mathrm{H}), 2.54(\mathrm{t}, J=7.20 \mathrm{~Hz}, 2 \mathrm{H}), 1.80-1.76(\mathrm{~m}, 2 \mathrm{H})$, 1.66-1.62 (m, 2H). LCMS m/z $395.2392(\mathrm{M}+\mathrm{H})$.

Flash column chromatography (15:1 $\left.\mathrm{CH}_{2} \mathrm{Cl}_{2}-\mathrm{MeOH}\right)$ afforded compound $\mathbf{1 0 b}(4.57 \mathrm{~g}, 83.0 \%)$ as a pale yellow solid. mp $111.8-112.5^{\circ} \mathrm{C} .{ }^{1} \mathrm{H}$ NMR $\left(\mathrm{CDCl}_{3}\right) \delta 7.76(\mathrm{dq}, J=39.6$ and $3.6 \mathrm{~Hz}$, 4H), $6.57(\mathrm{~s}, 1 \mathrm{H}), 6.51(\mathrm{~s}, 1 \mathrm{H}), 3.83(\mathrm{~s}, 3 \mathrm{H}), 3.82(\mathrm{~s}, 3 \mathrm{H}), 3.68(\mathrm{t}, J=7.20 \mathrm{~Hz}, 2 \mathrm{H}), 3.53(\mathrm{~s}, 2 \mathrm{H})$, $2.81(\mathrm{t}, J=5.75 \mathrm{~Hz}, 2 \mathrm{H}), 2.70(\mathrm{~d}, J=5.40 \mathrm{~Hz}, 2 \mathrm{H}), 2.48(\mathrm{t}, J=7.38 \mathrm{~Hz}, 2 \mathrm{H}), 1.71-1.65(\mathrm{~m}, 2 \mathrm{H})$, 1.59-1.57 (m, 2H), 1.41-1.37 (m, 4H). LCMS m/z $423.2752(\mathrm{M}+\mathrm{H})$. 


\subsubsection{4-(6,7-Dimethoxy-3,4-dihydroisoquinolin-2(1H)-yl)butan-1-amine (11a) and 6-(6,7-}

dimethoxy-3,4-dihydroisoquinolin-2(1H)-yl)hexan-1-amine (11b)

11a and 11b were synthesized using the literature method [42, 43]. Hydrazine monohydrate (10.1 mmol) was added to a solution of compound 10a (or 10b) $(1.52 \mathrm{mmol})$ in EtOH $(6.00 \mathrm{~mL})$, and stirred at $70{ }^{\circ} \mathrm{C}$ for $3 \mathrm{~h}$. The reaction mixture was cooled to ambient temperature and the EtOH removed in vacuo. Aqueous $\mathrm{NaOH}$ solution (50\%) was added until the white solid was fully dissolved, and the mixture extracted with $\mathrm{CH}_{2} \mathrm{Cl}_{2}(4 \times 50.0 \mathrm{~mL})$, and dried over anhydrous $\mathrm{Na}_{2} \mathrm{SO}_{4}$. The solvents were evaporated under reduced pressure to give compound 11a (or 11b) which was used without further purification.

11a; a pale yellow viscous oil (374 mg, 93.0\%) ${ }^{1} \mathrm{H}$ NMR $\left(\mathrm{CDCl}_{3}\right) \delta 6.57(\mathrm{~s}, 1 \mathrm{H}), 6.50(\mathrm{~s}, 1 \mathrm{H})$, $3.83(\mathrm{~s}, 3 \mathrm{H}), 3.81(\mathrm{~s}, 3 \mathrm{H}), 3.53(\mathrm{~s}, 2 \mathrm{H}), 2.79(\mathrm{t}, J=5.60 \mathrm{~Hz}, 2 \mathrm{H}), 2.71-2.66(\mathrm{~m}, 4 \mathrm{H}), 2.50-2.46$ (m, 2H), 1.61-1.57 (m, 2H), 1.49-1.47 (m, 2H). LCMS m/z 265.2048 (M+H).

11b; a pale yellow viscous oil $(647 \mathrm{mg}, 88.0 \%){ }^{1} \mathrm{H}$ NMR $\left(\mathrm{CDCl}_{3}\right) \delta 6.58(\mathrm{~s}, 1 \mathrm{H}), 6.51(\mathrm{~s}, 1 \mathrm{H})$, $3.83(\mathrm{~s}, 3 \mathrm{H}), 3.82(\mathrm{~s}, 3 \mathrm{H}), 3.54(\mathrm{~s}, 2 \mathrm{H}), 2.81(\mathrm{t}, J=5.76 \mathrm{~Hz}, 2 \mathrm{H}), 2.70-2.67(\mathrm{~m}, 4 \mathrm{H}), 2.50-2.46$ (m, 2H), 1.60-1.55 (m, 2H), 1.47-1.44 (m, 2H), 1.38-1.34 (m, 4H). LCMS m/z $293.2721(\mathrm{M}+\mathrm{H})$.

\subsubsection{Methyl 2-(2-fluoroethoxy)-5-methylbenzoate (12)}

2-Fluoroethyl 4-methylbenzenesulfonate $(982 \mathrm{mg}, 4.50 \mathrm{mmol})$ was added to a solution of methyl 5-methylsalicylate $(500 \mathrm{mg}, 3.00 \mathrm{mmol})$ and $\mathrm{K}_{2} \mathrm{CO}_{3}(892 \mathrm{mg}, 6.45 \mathrm{mmol})$ in $\mathrm{CH}_{3} \mathrm{CN}$ $(20.0 \mathrm{~mL})$, and the mixture was stirred at reflux for $3 \mathrm{~h}$. The reaction mixture was cooled to ambient temperature, the $\mathrm{CH}_{3} \mathrm{CN}$ removed in vacuo, and $\mathrm{H}_{2} \mathrm{O}(50.0 \mathrm{~mL})$ was added. After 
extraction with EtOAc $(2 \times 50.0 \mathrm{~mL})$, the combined organic layer was washed with brine $(50.0$ $\mathrm{mL}$ ), dried over anhydrous $\mathrm{Na}_{2} \mathrm{SO}_{4}$ and concentrated in vacuo. Flash column chromatography (5:1 hexane-EtOAc) gave compound $12(628 \mathrm{mg}, 98.5 \%)$ as a colorless viscous oil. ${ }^{1} \mathrm{H}$ NMR $\left(\mathrm{CDCl}_{3}\right) \delta 7.60(\mathrm{~s}, 1 \mathrm{H}), 7.26(\mathrm{~d}, J=11.5 \mathrm{~Hz}, 1 \mathrm{H}), 6.89(\mathrm{~d}, J=8.28 \mathrm{~Hz}, 1 \mathrm{H}), 4.82(\mathrm{dt}, J=46.1$ and $2.70 \mathrm{~Hz}, 2 \mathrm{H}), 4.26(\mathrm{dt}, J=26.6$ and $4.32 \mathrm{~Hz}, 2 \mathrm{H}), 3.88(\mathrm{~s}, 3 \mathrm{H}), 2.31(\mathrm{~s}, 3 \mathrm{H})$.

\subsection{4. (2-(2-Fluoroethoxy)-5-methylbenzoic acid (13)}

Solid $\mathrm{NaOH}(37.9 \mathrm{mg}, 0.47 \mathrm{mmol})$ was added to a solution of compound $12(100 \mathrm{mg}, 0.47$ mmol) in $\mathrm{MeOH}(5.00 \mathrm{~mL})$ and $\mathrm{H}_{2} \mathrm{O}(0.86 \mathrm{~mL})$, and the mixture was stirred at $70{ }^{\circ} \mathrm{C}$ for $3 \mathrm{~h}$. The reaction mixture was cooled, the $\mathrm{MeOH}$ removed in vacuo, and acidified to $\mathrm{pH} 2$ using $1 \mathrm{~N} \mathrm{HCl}$. After extraction with EtOAc $(2 \times 25.0 \mathrm{~mL})$, the combined organic layer was dried over anhydrous $\mathrm{Na}_{2} \mathrm{SO}_{4}$. Volatiles were evaporated in vacuo to give compound $\mathbf{1 3}$ (87.1 $\left.\mathrm{mg}, 93.3 \%\right)$ as a white solid which was used without further purification. mp 81.3-81.7 ${ }^{\circ} \mathrm{C} .{ }^{1} \mathrm{H} \mathrm{NMR}\left(\mathrm{CDCl}_{3}\right)$ $\delta 10.60(\mathrm{br}, 1 \mathrm{H}), 8.01(\mathrm{~s}, 1 \mathrm{H}), 7.35(\mathrm{~d}, J=10.8 \mathrm{~Hz}, 1 \mathrm{H}), 6.93(\mathrm{~d}, J=9.36 \mathrm{~Hz}, 1 \mathrm{H}), 4.83(\mathrm{dt}, J=$ 47.2 and $4.14 \mathrm{~Hz}, 2 \mathrm{H}), 4.45(\mathrm{dt}, J=28.8$ and $4.14 \mathrm{~Hz}, 2 \mathrm{H}), 2.34(\mathrm{~s}, 3 \mathrm{H})$.

\subsubsection{N-(4-(6,7-dimethoxy-3,4-dihydroisoquinolin-2(1H)-yl)butyl)-2-(2-fluoroethoxy)-5-}

methylbenzamide (3) and N-(6-(6,7-dimethoxy-3,4-dihydroisoquinolin-2(1H)-yl)hexyl)-2-(2fluoroethoxy)-5-methylbenzamide (7)

Compounds 3 and 7 were synthesized using the literature method [36]. DCC (0.15 mmol) and HOBt (0.15 mmol) were added to a solution of compound 11a (or 11b) $(0.18 \mathrm{mmol})$ and $\mathbf{1 3}$ 
$(0.15 \mathrm{mmol})$ in $\mathrm{CH}_{2} \mathrm{Cl}_{2}(2.00 \mathrm{~mL})$. The reaction mixture was stirred at room temperature for $20 \mathrm{~h}$. $\mathrm{H}_{2} \mathrm{O}(50.0 \mathrm{~mL})$ was added and the mixture was extracted with EtOAc $(2 \times 30.0 \mathrm{~mL})$. The combined organic layers was washed with brine, and then dried over anhydrous $\mathrm{Na}_{2} \mathrm{SO}_{4}$ and concentrated in vacuo.

Flash column chromatography $\left(15: 1 \mathrm{CH}_{2} \mathrm{Cl}_{2}-\mathrm{MeOH}\right)$ gave compound $\mathbf{3}(49.1 \mathrm{mg}, 73.7 \%)$ as a white solid. ${ }^{1} \mathrm{H}$ NMR $\left(\mathrm{CDCl}_{3}\right) \delta 7.99(\mathrm{~d}, J=3.60 \mathrm{~Hz}, 1 \mathrm{H}), 7.96(\mathrm{~s}, 1 \mathrm{H}), 7.21-7.20(\mathrm{~m}, 1 \mathrm{H}), 6.81$ $(\mathrm{d}, J=5.40 \mathrm{~Hz}, 1 \mathrm{H}), 6.57(\mathrm{~s}, 1 \mathrm{H}), 6.49(\mathrm{~s}, 1 \mathrm{H}), 4.85(\mathrm{t}, J=5.40 \mathrm{~Hz}, 1 \mathrm{H}), 4.69(\mathrm{t}, J=5.40 \mathrm{~Hz}$, $1 \mathrm{H}), 4.31(\mathrm{t}, J=5.40 \mathrm{~Hz}, 1 \mathrm{H}), 4.22(\mathrm{t}, J=5.40 \mathrm{~Hz}, 1 \mathrm{H}), 3.83(\mathrm{~s}, 3 \mathrm{H}), 3.82(\mathrm{~s}, 3 \mathrm{H}), 3.54-3.48(\mathrm{~m}$, 4H), $2.79(\mathrm{t}, J=5.40 \mathrm{~Hz}, 3 \mathrm{H}), 2.69(\mathrm{t}, J=7.20,3 \mathrm{H}), 2.53(\mathrm{t}, J=9.00 \mathrm{~Hz}, 3 \mathrm{H}), 2.33(\mathrm{~s}, 3 \mathrm{H})$, 2.00-1.67 (m, 4H). [36]

Flash column chromatography $\left(15: 1 \mathrm{CH}_{2} \mathrm{Cl}_{2}-\mathrm{MeOH}\right)$ gave compound $7(61.6 \mathrm{mg}, 86.3 \%)$ as a white solid. mp 100.2-100.6 ${ }^{\circ} \mathrm{C} .{ }^{1} \mathrm{H} \mathrm{NMR}\left(\mathrm{CDCl}_{3}\right) \delta 8.01(\mathrm{~s}, 1 \mathrm{H}), 7.89(\mathrm{br}, \mathrm{NH}), 7.21(\mathrm{~d}, J=$ $7.20 \mathrm{~Hz}, 1 \mathrm{H}), 6.83(\mathrm{~d}, \mathrm{~J}=7.20 \mathrm{~Hz}, 1 \mathrm{H}), 6.59(\mathrm{~s}, 1 \mathrm{H}), 6.52(\mathrm{~s}, 1 \mathrm{H}), 4.79(\mathrm{dt}, J=46.8$ and $3.60 \mathrm{~Hz}$, 2H), $4.30(\mathrm{dt}, J=25.2$ and $3.60 \mathrm{~Hz}, 2 \mathrm{H}), 3.84(\mathrm{~s}, 3 \mathrm{H}), 3.83(\mathrm{~s}, 3 \mathrm{H}), 3.68(\mathrm{~s}, 2 \mathrm{H}), 3.48-3.43(\mathrm{~m}$, 2H), $2.87(\mathrm{~s}, 4 \mathrm{H}), 2.61(\mathrm{~s}, 2 \mathrm{H}), 2.33(\mathrm{~s}, 3 \mathrm{H}), 1.69-1.59(\mathrm{~m}, 4 \mathrm{H}), 1.48-1.44(\mathrm{~m}, 4 \mathrm{H}) . \mathrm{LCMS} \mathrm{m} / \mathrm{z}$ 473.2164 (M+H). HRMS (ESI) (M+H) calcd for $\mathrm{C}_{27} \mathrm{H}_{38} \mathrm{FN}_{2} \mathrm{O}_{4}, 473.2816$; found, 473.2831.

\subsubsection{Ethyl 5-(2-fluoroethoxy)-1H-indole-2-carboxylate (14)}

2-Fluoroethyl 4-methylbenzenesulfonate $(1.28 \mathrm{~g}, 5.85 \mathrm{mmol})$ was added to a solution of $\mathrm{K}_{2} \mathrm{CO}_{3}(808 \mathrm{mg}, 5.84 \mathrm{mmol})$ and ethyl 5-hydroxy-1H-indole-2-carboxylate (1.28 g, $\left.5.84 \mathrm{mmol}\right)$ in $\mathrm{CH}_{3} \mathrm{CN}(90.0 \mathrm{~mL})$, and the mixture was stirred at reflux for $3 \mathrm{~h}$. The reaction mixture was 
cooled to ambient temperature, the $\mathrm{CH}_{3} \mathrm{CN}$ removed in vacuo, and $\mathrm{H}_{2} \mathrm{O}(50.0 \mathrm{~mL})$ added. After extraction with EtOAc $(2 \times 50.0 \mathrm{~mL})$, the combined organic layer was washed with $\mathrm{H}_{2} \mathrm{O}(2 \times$ $50.0 \mathrm{~mL}$ ), dried over anhydrous $\mathrm{Na}_{2} \mathrm{SO}_{4}$ and concentrated in vacuo. Flash column chromatography (3:1 hexane-EtOAc) afforded compound $\mathbf{1 4}(1.48 \mathrm{~g}, 99.0 \%)$ as a white oil. ${ }^{1} \mathrm{H}$ $\operatorname{NMR}\left(\mathrm{CDCl}_{3}\right) \delta 7.81(\mathrm{~d}, J=8.30 \mathrm{~Hz}, 2 \mathrm{H}), 7.34(\mathrm{~d}, J=19.8 \mathrm{~Hz}, 2 \mathrm{H}), 4.57(\mathrm{dt}, J=45.7$ and 4.00 $\mathrm{Hz}, 2 \mathrm{H}), 4.27(\mathrm{dt}, J=29.8$ and $5.40 \mathrm{~Hz}, 2 \mathrm{H}), 4.40(\mathrm{q}, J=7.20 \mathrm{~Hz}, 2 \mathrm{H}), 1.41(\mathrm{t}, \mathrm{J}=7.20 \mathrm{~Hz}, 3 \mathrm{H})$.

\subsubsection{5-(2-Fluoroethoxy)-1H-indole-2-carboxylic acid (15)}

Solid $\mathrm{NaOH}(160 \mathrm{mg}, 4.00 \mathrm{mmol})$ was added to a solution of $14(500 \mathrm{mg}, 1.99 \mathrm{mmol})$ in $\mathrm{MeOH} / \mathrm{H}_{2} \mathrm{O}(30.0 / 5.00 \mathrm{~mL})$, and stirred at $70{ }^{\circ} \mathrm{C}$ for $3 \mathrm{~h}$. The reaction mixture was cooled to ambient temperature, the $\mathrm{MeOH}$ removed in vacuo, and $1 \mathrm{~N} \mathrm{HCl}$ was added to the reaction mixture until $\mathrm{pH} \sim 2$. After extraction with $\mathrm{CH}_{2} \mathrm{Cl}_{2}(2 \times 50.0 \mathrm{~mL})$, the combined organic layer was washed with $\mathrm{H}_{2} \mathrm{O}(2 \times 50.0 \mathrm{~mL})$, dried over anhydrous $\mathrm{Na}_{2} \mathrm{SO}_{4}$ and concentrated in vacuo to

give compound $15(115 \mathrm{mg}, 25.8 \%)$ as a white solid. mp 220.5-220.9 ${ }^{\circ} \mathrm{C} .{ }^{1} \mathrm{H}$ NMR (DMSO-d 6 ) $\delta$ $7.33(\mathrm{~d}, J=9.00 \mathrm{~Hz}, 1 \mathrm{H}), 7.12(\mathrm{~s}, 1 \mathrm{H}), 6.97(\mathrm{~s}, 1 \mathrm{H}), 6.92(\mathrm{~d}, J=9.00 \mathrm{~Hz}, 1 \mathrm{H}), 4.74(\mathrm{dt}, J=47.8$ and $3.60 \mathrm{~Hz}, 2 \mathrm{H}), 4.21(\mathrm{dt}, J=30.2$ and $4.00 \mathrm{~Hz}, 2 \mathrm{H})$.

\subsubsection{Methyl 5-methoxybenzo[b]thiophene-2-carboxylate (16)}

Methyl thioglycolate $(208 \mu \mathrm{L}, 2.34 \mathrm{mmol})$ was dropwise added to a solution of $\mathrm{NaH}(93.4 \mathrm{mg}$, $3.89 \mathrm{mmol}$ ) in DMSO (9.00 mL), followed by adding 2-fluoro-5-methoxybenzaldehyde (300 mg, $1.95 \mathrm{mmol}$ ) quickly. The reaction mixture was stirred at room temperature for $5 \mathrm{~min}$, and 
precipitated by pouring into ice cold $\mathrm{H}_{2} \mathrm{O}$. The product was filtered, and washed with $\mathrm{H}_{2} \mathrm{O}$ to afford compound $\mathbf{1 6}(133 \mathrm{mg}, 30.0 \%)$ as a white solid. mp 109.2-109.3 ${ }^{\circ} \mathrm{C} .{ }^{1} \mathrm{H} \mathrm{NMR}\left(\mathrm{CDCl}_{3}\right) \delta$ $7.98(\mathrm{~s}, 1 \mathrm{H}), 7.71(\mathrm{~d}, J=10.8 \mathrm{~Hz}, 1 \mathrm{H}), 7.28(\mathrm{~s}, 1 \mathrm{H}), 7.12(\mathrm{~d}, J=7.20 \mathrm{~Hz}, 1 \mathrm{H}), 3.94(\mathrm{~s}, 3 \mathrm{H}), 3.88$ $(\mathrm{s}, 3 \mathrm{H})$.

\subsubsection{5-Methoxybenzo[b]thiophene-2-carboxylic acid (17)}

Solid $\mathrm{NaOH}(42.6 \mathrm{mg}, 1.06 \mathrm{mmol})$ was added to a solution of $\mathbf{1 6}(120 \mathrm{mg}, 0.53 \mathrm{mmol})$ in $\mathrm{MeOH} / \mathrm{H}_{2} \mathrm{O}(6.00 / 1.00 \mathrm{~mL})$, and stirred at $70{ }^{\circ} \mathrm{C}$ for $3 \mathrm{~h}$. The reaction mixture was cooled to ambient temperature, the $\mathrm{MeOH}$ was removed in vacuo, and $1 \mathrm{~N} \mathrm{HCl}$ added to the reaction mixture until $\mathrm{pH} \sim 2$. After extraction with $\mathrm{CH}_{2} \mathrm{Cl}_{2}(2 \times 50.0 \mathrm{~mL})$, the combined organic layer was washed with $\mathrm{H}_{2} \mathrm{O}(2 \times 50.0 \mathrm{~mL})$, dried over anhydrous $\mathrm{Na}_{2} \mathrm{SO}_{4}$ and concentrated in vacuo to give compound 17 (103 mg, 92.8\%) as a white solid. mp 180.6-181.3 ${ }^{\circ} \mathrm{C} .{ }^{1} \mathrm{H}$ NMR (DMSO-d $\left.\mathrm{d}_{6}\right) \delta$ 13.36 (br, $\mathrm{COOH}), 7.99$ (s, 1H), $7.89(\mathrm{~d}, J=7.20 \mathrm{~Hz}, 1 \mathrm{H}), 7.50(\mathrm{~s}, 1 \mathrm{H}), 7.13(\mathrm{~d}, J=7.20 \mathrm{~Hz}$, 1H), $3.80(\mathrm{~s}, 3 \mathrm{H})$.

\subsubsection{5-(2-Fluoroethoxy)-2-nitrobenzaldehyde (18)}

2-Fluoroethyl 4-methylbenzenesulfonate $(1.08 \mathrm{~g}, 4.98 \mathrm{mmol})$ was added to a solution of $\mathrm{K}_{2} \mathrm{CO}_{3}(1.65 \mathrm{mg}, 12.0 \mathrm{mmol})$ and 5-hydroxy-2-nitrobenzaldehyde $(1.00 \mathrm{~g}, 5.98 \mathrm{mmol})$ in $\mathrm{CH}_{3} \mathrm{CN}(50.0 \mathrm{~mL})$, and the mixture stirred at reflux for $6 \mathrm{hr}$. The reaction mixture was cooled to ambient temperature, the $\mathrm{CH}_{3} \mathrm{CN}$ removed in vacuo, and $\mathrm{H}_{2} \mathrm{O}(100 \mathrm{~mL})$ added. After extraction with EtOAc $(2 \times 100 \mathrm{~mL})$, the combined organic layer was washed with $\mathrm{H}_{2} \mathrm{O}(2 \times 50.0 \mathrm{~mL})$, 
dried over anhydrous $\mathrm{Na}_{2} \mathrm{SO}_{4}$ and concentrated. Flash column chromatography (2:1 hexaneEtOAc) afforded compound $18(687 \mathrm{mg}, 64.6 \%)$ as a pale yellow solid. mp 67.0-67.9 ${ }^{\circ} \mathrm{C} .{ }^{1} \mathrm{H}$ $\operatorname{NMR}\left(\mathrm{CDCl}_{3}\right) \delta 7.98(\mathrm{~s}, 1 \mathrm{H}), 7.71(\mathrm{~d}, J=21.6 \mathrm{~Hz}, 1 \mathrm{H}), 7.16(\mathrm{~d}, J=10.8 \mathrm{~Hz}, 1 \mathrm{H}), 4.80(\mathrm{dt}, J=$ 47.5 and $3.60 \mathrm{~Hz}, 2 \mathrm{H}), 4.29(\mathrm{dt}, \mathrm{J}=21.6$ and $3.60 \mathrm{~Hz}, 2 \mathrm{H}), 3.87(\mathrm{~s}, 3 \mathrm{H})$.

\subsubsection{Methyl 5-(2-fluoroethoxy)benzo[b]thiophene-2-carboxylate (19)}

$\mathrm{K}_{2} \mathrm{CO}_{3}(194 \mathrm{mg}, 1.41 \mathrm{mmol})$ was added to a solution of 18 (300 mg, $\left.1.41 \mathrm{mmol}\right)$ in DMF (4.50 mL), added methyl thioglycolate $(125 \mu \mathrm{L}, 1.41 \mathrm{mmol})$, and stirred at $80{ }^{\circ} \mathrm{C}$ for $20 \mathrm{~h}$. The reaction mixture was cooled to ambient temperature, poured into ice $\mathrm{H}_{2} \mathrm{O}$, extracted with EtOAc (3 x $50 \mathrm{~mL}$ ), dried over anhydrous $\mathrm{Na}_{2} \mathrm{SO}_{4}$, and concentrated in vacuo. Flash column chromatography (6:1 hexane-EtOAc) afforded compound $19(51.3 \mathrm{mg}, 14.3 \%)$ as a pale yellow solid. mp 124.8-124.9 ${ }^{\circ} \mathrm{C} .{ }^{1} \mathrm{H} \operatorname{NMR}\left(\mathrm{CDCl}_{3}\right) \delta 8.18(\mathrm{~s}, 1 \mathrm{H}), 7.74(\mathrm{~d}, J=10.8 \mathrm{~Hz}, 1 \mathrm{H}), 7.30(\mathrm{~s}$, 1H), $7.16(\mathrm{~d}, J=9.00 \mathrm{~Hz}, 1 \mathrm{H}), 4.79(\mathrm{dt}, J=47.5$ and $4.30 \mathrm{~Hz}, 2 \mathrm{H}), 4.28(\mathrm{dt}, \mathrm{J}=27.7$ and 3.90 $\mathrm{Hz}), 3.94$ (s, 3H).

\subsubsection{5-(2-Fluoroethoxy)benzo[b]thiophene-2-carboxylic acid (20)}

Solid $\mathrm{NaOH}(15.8 \mathrm{mg}, 0.40 \mathrm{mmol})$ was added to a solution of $\mathbf{1 9}(50.0 \mathrm{mg}, 0.20 \mathrm{mmol})$ in $\mathrm{MeOH} / \mathrm{H}_{2} \mathrm{O}(2.50 / 0.40 \mathrm{~mL})$, and stirred at $70{ }^{\circ} \mathrm{C}$ for $3 \mathrm{~h}$. The reaction mixture was cooled to ambient temperature, $\mathrm{MeOH}$ removed in vacuo, and $1 \mathrm{~N} \mathrm{HCl}$ added to the reaction mixture until $\mathrm{pH} \sim 2$. After extraction with $\mathrm{CH}_{2} \mathrm{Cl}_{2}(2 \times 30.0 \mathrm{~mL})$, the combined organic layer was washed with $\mathrm{H}_{2} \mathrm{O}(2 \times 30.0 \mathrm{~mL})$, dried over anhydrous $\mathrm{Na}_{2} \mathrm{SO}_{4}$ and concentrated in vacuo to give compound 
20 (103 mg, 92.8\%) as a white solid. mp 192.1-192.6 ${ }^{\circ} \mathrm{C} .{ }^{1} \mathrm{H}$ NMR (DMSO-d 6 ) $\delta 7.98(\mathrm{~s}, 1 \mathrm{H})$, $7.93(\mathrm{~d}, J=9.00 \mathrm{~Hz}, 1 \mathrm{H}), 7.54(\mathrm{~d}, J=2.50 \mathrm{~Hz}, 1 \mathrm{H}), 7.18(\mathrm{dd}, J=9.00$ and $2.50 \mathrm{~Hz}, 1 \mathrm{H}), 4.78(\mathrm{dt}$, $J=47.8$ and $3.90 \mathrm{~Hz}, 2 \mathrm{H}), 4.30(\mathrm{dt}, J=29.8$ and $3.90 \mathrm{~Hz}, 2 \mathrm{H})$.

\subsubsection{N-(4-(6,7-Dimethoxy-3,4-dihydroisoquinolin-2(1H)-yl)butyl)-5-methoxy-1H-indole-2-}

carboxamide (8a), N-(6-(6,7-dimethoxy-3,4-dihydroisoquinolin-2(1H)-yl)hexyl)-5-methoxy-1Hindole-2-carboxamide (8b), N-(4-(6,7-dimethoxy-3,4-dihydroisoquinolin-2(1H)-yl)butyl)-5-(2fluoroethoxy)-1H-indole-2-carboxamide (8c), and N-(6-(6,7-dimethoxy-3,4-dihydroisoquinolin2(1H)-yl)hexyl)-5-(2-fluoroethoxy)-1H-indole-2-carboxamide (8d).

DCC $(0.23 \mathrm{mmol})$ and $\mathrm{HOBt}(0.23 \mathrm{mmol})$ were added to a solution of compound 11a (or 11b) (0.23 mmol) and 5-methoxy-1H-indole-2-carboxylic acid (or 15) $(0.23 \mathrm{mmol})$ in $\mathrm{CH}_{2} \mathrm{Cl}_{2}$ (5.00 $\mathrm{mL})$. The reaction mixture was stirred at ambient temperature for $20 \mathrm{~h} . \quad \mathrm{H}_{2} \mathrm{O}(50.0 \mathrm{~mL})$ was added to the reaction mixture, and the mixture extracted with EtOAc $(2 \times 30.0 \mathrm{~mL})$, washed with brine, and the combined organic layer was dried over anhydrous $\mathrm{Na}_{2} \mathrm{SO}_{4}$ and concentrated in vacuo.

Flash column chromatography (30:1 $\left.\mathrm{CH}_{2} \mathrm{Cl}_{2}-\mathrm{MeOH}\right)$ gave compound $\mathbf{8 a}(89.4 \mathrm{mg}, 90.0 \%)$ as a white solid. mp 193.2-193.3 ${ }^{\circ} \mathrm{C} .{ }^{1} \mathrm{H}$ NMR $\left(\mathrm{CDCl}_{3}\right) \delta 9.12$ (br, NH), 7.88 (s, 1H), 7.23 (s, 1H), $6.88(\mathrm{dd}, J=3.60$ and $3.60 \mathrm{~Hz}, 1 \mathrm{H}), 6.67(\mathrm{~d}, J=3.60 \mathrm{~Hz}, 1 \mathrm{H}), 6.64(\mathrm{~s}, 1 \mathrm{H}), 6.51(\mathrm{~s}, 1 \mathrm{H}), 6.32$ (br, NH), $3.85(\mathrm{~s}, 3 \mathrm{H}), 3.82(\mathrm{~s}, 3 \mathrm{H}), 3.70(\mathrm{~s}, 2 \mathrm{H}), 3.53(\mathrm{q}, J=5.70 \mathrm{~Hz}, 2 \mathrm{H}), 2.93(\mathrm{~d}, J=3.60 \mathrm{~Hz}$, 2H), $2.87(\mathrm{~d}, J=7.20 \mathrm{~Hz}, 2 \mathrm{H}), 2.69(\mathrm{t}, J=5.40 \mathrm{~Hz}, 2 \mathrm{H}), 1.86-1.78(\mathrm{~m}, 4 \mathrm{H}) . \mathrm{LCMS} \mathrm{m} / \mathrm{z}$ 438.2298 (M+H). HRMS (ESI) $(\mathrm{M}+\mathrm{H})$ calcd for $\mathrm{C}_{25} \mathrm{H}_{31} \mathrm{~N}_{3} \mathrm{O}_{4}, 438.2393$; found, 438.2383.

Flash column chromatography (30:1 $\left.\mathrm{CH}_{2} \mathrm{Cl}_{2}-\mathrm{MeOH}\right)$ gave compound $\mathbf{8 b}(65.1 \mathrm{mg}, 68.2 \%)$ as a white solid. mp $174.8-175.1^{\circ} \mathrm{C} .{ }^{1} \mathrm{H} \mathrm{NMR}\left(\mathrm{CDCl}_{3}\right) \delta 9.27(\mathrm{br}, \mathrm{NH}), 7.32(\mathrm{~d}, J=3.60 \mathrm{~Hz}, 1 \mathrm{H})$, 
$7.05(\mathrm{~s}, 1 \mathrm{H}), 6.95(\mathrm{~d}, J=3.60 \mathrm{~Hz}, 1 \mathrm{H}), 6.79(\mathrm{~s}, 1 \mathrm{H}), 6.59(\mathrm{~s}, 1 \mathrm{H}), 6.49(\mathrm{~s}, 1 \mathrm{H}), 6.35(\mathrm{br}, \mathrm{NH})$ $3.87(\mathrm{~s}, 6 \mathrm{H}), 3.84(\mathrm{~s}, 3 \mathrm{H}), 3.63(\mathrm{~s}, 2 \mathrm{H}), 3.49(\mathrm{q}, J=7.20 \mathrm{~Hz}, 2 \mathrm{H}), 2.86-2.80(\mathrm{~m}, 4 \mathrm{H}), 2.58(\mathrm{t}, J=$ $10.8 \mathrm{~Hz}, 2 \mathrm{H}), 1.67(\mathrm{t}, J=7.20 \mathrm{~Hz}, 4 \mathrm{H}), 1.44(\mathrm{t}, J=3.60 \mathrm{~Hz}, 4 \mathrm{H})$. LCMS m/z $466.2721(\mathrm{M}+\mathrm{H})$. HRMS (ESI) (M+H) calcd for $\mathrm{C}_{27} \mathrm{H}_{36} \mathrm{~N}_{3} \mathrm{O}_{4}, 466.2706$; found, 466.2686

Flash column chromatography $\left(15: 1 \mathrm{CH}_{2} \mathrm{Cl}_{2}-\mathrm{MeOH}\right)$ gave compound $\mathbf{8 c}(85.0 \mathrm{mg}, 80.8 \%)$ as a white solid. mp 198.1-198.4 ${ }^{\circ} \mathrm{C} .{ }^{1} \mathrm{H}$ NMR $\left(\mathrm{CDCl}_{3}\right) \delta 9.24$ (br, NH), $7.98(\mathrm{~s}, 1 \mathrm{H}), 7.27(\mathrm{~d}, J=$ $3.60 \mathrm{~Hz}, 1 \mathrm{H}), 6.93(\mathrm{~d}, J=7.20 \mathrm{~Hz}, 2 \mathrm{H}), 6.63(\mathrm{~d}, J=3.60 \mathrm{~Hz}, 2 \mathrm{H}), 6.51(\mathrm{~s}, 1 \mathrm{H}), 6.24(\mathrm{br}, \mathrm{NH})$, $4.78(\mathrm{dt}, J=46.8$ and $3.60 \mathrm{~Hz}, 2 \mathrm{H}), 4.25(\mathrm{dt}, J=28.8$ and $3.60 \mathrm{~Hz}, 2 \mathrm{H}), 3.85(\mathrm{~s}, 3 \mathrm{H}), 3.79(\mathrm{~s}$, $3 \mathrm{H}), 3.68(\mathrm{~s}, 2 \mathrm{H}), 3.55-3.52(\mathrm{~m}, 2 \mathrm{H}), 2.93-2.92(\mathrm{~m}, 2 \mathrm{H}), 2.85-2.84(\mathrm{~m}, 2 \mathrm{H}), 2.67(\mathrm{t}, J=7.20 \mathrm{~Hz}$, 2H), 1.85-1.78 (m, 4H). LCMS m/z $470.2784(\mathrm{M}+\mathrm{H})$. HRMS (ESI) $(\mathrm{M}+\mathrm{H})$ calcd for $\mathrm{C}_{26} \mathrm{H}_{33} \mathrm{FN}_{3} \mathrm{O}_{4}$, 470.2455; found, 470.2454.

Flash column chromatography (15:1 $\left.\mathrm{CH}_{2} \mathrm{Cl}_{2}-\mathrm{MeOH}\right)$ gave compound 8d (54.1 mg, $\left.48.5 \%\right)$ as a white solid. ${ }^{1} \mathrm{H}$ NMR $\left(\mathrm{CDCl}_{3}\right) \delta 9.33(\mathrm{br}, \mathrm{NH}), 7.33(\mathrm{~d}, J=10.8 \mathrm{~Hz}, 1 \mathrm{H}), 7.07(\mathrm{~s}, 1 \mathrm{H}), 7.00$ (d, $J=3.60 \mathrm{~Hz}, 1 \mathrm{H}), 6.79(\mathrm{~s}, 1 \mathrm{H}), 6.59(\mathrm{~s}, 1 \mathrm{H}), 6.49(\mathrm{~s}, 1 \mathrm{H}), 6.38(\mathrm{br}, \mathrm{NH}), 4.77(\mathrm{dt}, J=46.8$ and $3.60 \mathrm{~Hz}, 2 \mathrm{H}), 4.24(\mathrm{dt}, J=28.8$ and $3.60 \mathrm{~Hz}, 2 \mathrm{H}), 3.84(\mathrm{~s}, 3 \mathrm{H}), 3.82(\mathrm{~s}, 3 \mathrm{H}), 3.64(\mathrm{~s}, 2 \mathrm{H}), 3.49$ (q, $J=7.20 \mathrm{~Hz}, 2 \mathrm{H}), 2.86-2.81(\mathrm{~m}, 4 \mathrm{H}), 2.58(\mathrm{t}, J=7.20 \mathrm{~Hz}, 2 \mathrm{H}), 1.68-1.65(\mathrm{~m}, 4 \mathrm{H}), 1.45-1.43(\mathrm{~m}$, 4H). LCMS m/z 498.1904 (M+H). HRMS (ESI) (M+H) calcd for $\mathrm{C}_{28} \mathrm{H}_{37} \mathrm{FN}_{3} \mathrm{O}_{4}, 498.2768$; found, 498.2766.

1.2.14. N-(4-(6,7-Dimethoxy-3,4-dihydroisoquinolin-2(1H)-yl)butyl)-5-

methoxybenzo[b]thiophene-2-carboxamide (9a), N-(6-(6,7-dimethoxy-3,4-dihydroisoquinolin2(1H)-yl)hexyl)-5-methoxybenzo[b] thiophene-2-carboxamide $\quad(\mathbf{9 b}), \quad N$-(4-(6,7-dimethoxy-3,4- 
dihydroisoquinolin-2(1H)-yl)butyl)-5-(2-fluoroethoxy)benzo[b]thiophene-2-carboxamide $\quad(\mathbf{9 c})$, and $\quad N$-(6-(6,7-dimethoxy-3,4-dihydroisoquinolin-2(1H)-yl)hexyl)-5-(2-fluoroethoxy)benzo[b]thiophene-2-carboxamide (9d)

DCC $(0.19 \mathrm{mmol})$ and $\mathrm{HOBt}(0.19 \mathrm{mmol})$ were added to a solution of compound 11a (or 11b) $(0.23 \mathrm{mmol})$ and $\mathbf{1 7}$ (or 20) $(0.19 \mathrm{mmol})$ in $\mathrm{CH}_{2} \mathrm{Cl}_{2}(5.00 \mathrm{~mL})$. The reaction mixture was stirred at ambient temperature for $20 \mathrm{~h} . \quad \mathrm{H}_{2} \mathrm{O}(50.0 \mathrm{~mL})$ was added to the reaction mixture, and the mixture extracted with EtOAc $(2 \times 30.0 \mathrm{~mL})$, washed with brine, and the combined organic layer was dried over anhydrous $\mathrm{Na}_{2} \mathrm{SO}_{4}$ and concentrated $\mathrm{n}$ vacuo.

Flash column chromatography $\left(20: 1 \mathrm{CH}_{2} \mathrm{Cl}_{2}-\mathrm{MeOH}\right)$ gave compound $9 \mathbf{a}(56.6 \mathrm{mg}, 64.8 \%)$ as a white solid. mp 122.0-122.4 ${ }^{\circ} \mathrm{C} .{ }^{1} \mathrm{H}$ NMR $\left(\mathrm{CDCl}_{3}\right) \delta 7.83(\mathrm{br}, \mathrm{NH}), 7.60(\mathrm{~d}, J=10.8 \mathrm{~Hz}, 1 \mathrm{H})$, $7.50(\mathrm{~s}, 1 \mathrm{H}), 7.01(\mathrm{~d}, J=7.20 \mathrm{~Hz}, 1 \mathrm{H}), 6.94(\mathrm{~s}, 1 \mathrm{H}), 6.60(\mathrm{~s}, 1 \mathrm{H}), 6.47(\mathrm{~s}, 1 \mathrm{H}), 3.84(\mathrm{~s}, 3 \mathrm{H}), 3.83$ (s, 3H), $3.77(\mathrm{~s}, 3 \mathrm{H}), 3.74(\mathrm{~s}, 2 \mathrm{H}), 3.53(\mathrm{q}, J=7.20 \mathrm{~Hz}, 2 \mathrm{H}), 2.93$ (s, 4H), $2.74(\mathrm{t}, J=7.20 \mathrm{~Hz}$, 2H), 1.88-1.78 (m, 4H). LCMS m/z $455.0548(\mathrm{M}+\mathrm{H})$. HRMS (ESI) $(\mathrm{M}+\mathrm{H})$ calcd for $\mathrm{C}_{25} \mathrm{H}_{30} \mathrm{~N}_{2} \mathrm{O}_{4} \mathrm{~S}, 455.2005$; found, 455.1999.

Flash column chromatography $\left(20: 1 \mathrm{CH}_{2} \mathrm{Cl}_{2}-\mathrm{MeOH}\right)$ gave compound $9 \mathbf{b}(66.5 \mathrm{mg}, 71.7 \%)$ as a white solid. mp 57.1-57.3 ${ }^{\circ} \mathrm{C} .{ }^{1} \mathrm{H}$ NMR $\left(\mathrm{CDCl}_{3}\right) \delta 7.74(\mathrm{~s}, 1 \mathrm{H}), 7.69(\mathrm{~d}, J=10.8 \mathrm{~Hz}, 1 \mathrm{H})$, $7.24(\mathrm{~d}, J=3.60 \mathrm{~Hz}, 1 \mathrm{H}), 7.07(\mathrm{dd}, J=7.20$ and $3.60 \mathrm{~Hz}, 1 \mathrm{H}), 6.58(\mathrm{~s}, 1 \mathrm{H}), 6.50(\mathrm{~s}, 1 \mathrm{H}), 6.29$ (br, NH), $3.86(\mathrm{~s}, 3 \mathrm{H}), 3.83(\mathrm{~s}, 3 \mathrm{H}), 3.82(\mathrm{~s}, 3 \mathrm{H}), 3.64(\mathrm{~s}, 2 \mathrm{H}), 3.47$ (q, $J=7.20 \mathrm{~Hz}, 2 \mathrm{H}), 2.86-$ $2.81(\mathrm{~m}, 4 \mathrm{H}), 2.58(\mathrm{t}, J=7.20 \mathrm{~Hz}, 2 \mathrm{H}), 1.68-1.65(\mathrm{~m}, 4 \mathrm{H}), 1.45-1.43(\mathrm{~m}, 4 \mathrm{H})$. LCMS m/z 483.2325 (M+H). HRMS (ESI) (M+H) calcd for $\mathrm{C}_{27} \mathrm{H}_{34} \mathrm{~N}_{2} \mathrm{O}_{4} \mathrm{~S}, 483.2318$; found, 483.2305.

Flash column chromatography $\left(20: 1 \mathrm{CH}_{2} \mathrm{Cl}_{2}-\mathrm{MeOH}\right)$ gave compound $9 \mathrm{c}(35.6 \mathrm{mg}, 93.8 \%)$ as a white solid. mp 144.5-145.0 ${ }^{\circ} \mathrm{C} .{ }^{1} \mathrm{H}$ NMR $\left(\mathrm{CDCl}_{3}\right) \delta 8.02(\mathrm{br}, \mathrm{NH}), 7.63(\mathrm{~d}, J=7.20 \mathrm{~Hz}, 1 \mathrm{H})$, 
$7.46(\mathrm{~s}, 1 \mathrm{H}), 7.05(\mathrm{dd}, J=7.20$ and $3.60 \mathrm{~Hz}, 1 \mathrm{H}), 6.86(\mathrm{~s}, 1 \mathrm{H}), 6.61(\mathrm{~s}, 1 \mathrm{H}), 6.47(\mathrm{~s}, 1 \mathrm{H}), 4.78(\mathrm{dt}$, $J=47.5$ and $3.90 \mathrm{~Hz}, 2 \mathrm{H}), 4.23(\mathrm{dt}, J=28.4$ and $3.90 \mathrm{~Hz}, 2 \mathrm{H}), 3.83(\mathrm{~s}, 3 \mathrm{H}), 3.76(\mathrm{~s}, 3 \mathrm{H}), 3.53(\mathrm{q}$, $J=5.40 \mathrm{~Hz}, 2 \mathrm{H}), 2.94(\mathrm{~s}, 4 \mathrm{H}), 2.75(\mathrm{~s}, 2 \mathrm{H}), 1.90-1.80(\mathrm{~m}, 6 \mathrm{H}) . \mathrm{LCMS} \mathrm{m} / \mathrm{z} 487.1054(\mathrm{M}+\mathrm{H})$. HRMS (ESI) (M+H) calcd for $\mathrm{C}_{26} \mathrm{H}_{32} \mathrm{FN}_{2} \mathrm{O}_{4} \mathrm{~S}$, 487.2067; found, 487.2056.

Flash column chromatography (20:1 $\left.\mathrm{CH}_{2} \mathrm{Cl}_{2}-\mathrm{MeOH}\right)$ gave compound $9 \mathbf{d}(25.7 \mathrm{mg}, 64.0 \%)$ as

a white solid. mp 99.7-99.9 ${ }^{\circ} \mathrm{C} .{ }^{1} \mathrm{H}$ NMR $\left(\mathrm{CDCl}_{3}\right) \delta 8.02(\mathrm{br}, \mathrm{NH}), 7.80(\mathrm{~s}, 1 \mathrm{H}), 7.72(\mathrm{~d}, J=7.20$ $\mathrm{Hz}, 1 \mathrm{H}), 7.27$ (s, 1H), $7.11(\mathrm{dd}, J=7.20$ and $3.60 \mathrm{~Hz}, 1 \mathrm{H}), 6.59$ (s, 1H), 6.49 (s, 1H), 4.78 (dt, $J$ $=47.2$ and $3.90 \mathrm{~Hz}, 2 \mathrm{H}), 4.26(\mathrm{dt}, J=27.7$ and $3.90 \mathrm{~Hz}, 2 \mathrm{H}), 3.83(\mathrm{~s}, 3 \mathrm{H}), 3.82(\mathrm{~s}, 3 \mathrm{H}), 3.74(\mathrm{~s}$, 2H), $3.47(\mathrm{q}, J=7.20 \mathrm{~Hz}, 2 \mathrm{H}), 2.91(\mathrm{~s}, 4 \mathrm{H}), 2.67(\mathrm{t}, J=7.20 \mathrm{~Hz}, 2 \mathrm{H}), 1.72-1.66(\mathrm{~m}, 4 \mathrm{H}), 1.47-$ $1.45(\mathrm{~m}, 4 \mathrm{H})$. LCMS m/z 515.2862 (M+H). HRMS (ESI) $(\mathrm{M}+\mathrm{H})$ calcd for $\mathrm{C}_{28} \mathrm{H}_{36} \mathrm{FN}_{2} \mathrm{O}_{4} \mathrm{~S}$, 515.2380; found, 515.2370.

\subsubsection{Methyl 2-(2-acetoxyethoxy)-5-methylbenzoate (21)}

2-Bromoethyl acetate (2.68 $\mathrm{g}, 16.1 \mathrm{mmol})$ was added to a solution of methyl 5methylsalicylate (540 mg, $3.25 \mathrm{mmol})$ and $\mathrm{K}_{2} \mathrm{CO}_{3}(2.19 \mathrm{~g}, 15.8 \mathrm{mmol})$ in $\mathrm{CH}_{3} \mathrm{CN}(38.0 \mathrm{~mL})$, and stirred at $80{ }^{\circ} \mathrm{C}$ for $48 \mathrm{~h}$. The reaction mixture was cooled to ambient temperature, $\mathrm{CH}_{3} \mathrm{CN}$ was removed in vacuo, and $\mathrm{H}_{2} \mathrm{O}(50.0 \mathrm{~mL})$ added. After extraction with EtOAc $(2 \times 50.0 \mathrm{~mL})$, the combined organic layer was washed with brine $(50.0 \mathrm{~mL})$, dried over anhydrous $\mathrm{Na}_{2} \mathrm{SO}_{4}$ and concentrated in vacuo. Flash column chromatography (3:1 hexane-EtOAc) gave compound 21 (235 mg, 28.7\%) as a pale yellow liquid. ${ }^{1} \mathrm{H}$ NMR $\left(\mathrm{CDCl}_{3}\right) \delta 7.56(\mathrm{~s}, 1 \mathrm{H}), 7.24(\mathrm{~d}, J=8.64 \mathrm{~Hz}$, $1 \mathrm{H}), 6.87(\mathrm{~d}, J=6.87 \mathrm{~Hz}, 1 \mathrm{H}), 4.44(\mathrm{t}, J=3.60 \mathrm{~Hz}, 2 \mathrm{H}), 4.21(\mathrm{t}, J=3.60 \mathrm{~Hz}, 2 \mathrm{H}), 3.87(\mathrm{~s}, 3 \mathrm{H})$, $2.30(\mathrm{~s}, 3 \mathrm{H}), 2.09$ (s, 3H). 
1.2.16. 2-(2-Hydroxyethoxy)-5-methylbenzoic acid (22)

Solid $\mathrm{NaOH}(81.1 \mathrm{mg}, 2.03 \mathrm{mmol})$ was added to a solution of compound 21 (235 mg, 0.93 mmol) in $\mathrm{MeOH}(10.0 \mathrm{~mL})$ and $\mathrm{H}_{2} \mathrm{O}(4.70 \mathrm{~mL})$, and the mixture was stirred at $70{ }^{\circ} \mathrm{C}$ for $3 \mathrm{~h}$. The reaction mixture was cooled to ambient temperature, the $\mathrm{MeOH}$ removed in vacuo, and acidified to $\mathrm{pH} 2$ using $1 \mathrm{~N} \mathrm{HCl}$. After extraction with EtOAc $(2 \times 50.0 \mathrm{~mL})$, the combined organic layer was dried over anhydrous $\mathrm{Na}_{2} \mathrm{SO}_{4}$. The volatiles were removed in vacuo to give compound 22 (179 mg, 98\%) as a colorless liquid which was used without further purification. ${ }^{1} \mathrm{H}$ NMR $\left(\mathrm{CDCl}_{3}\right) \delta 7.95(\mathrm{~s}, 1 \mathrm{H}), 7.34(\mathrm{~d}, J=7.20 \mathrm{~Hz}, 1 \mathrm{H}), 6.95(\mathrm{~d}, J=8.28 \mathrm{~Hz}, 1 \mathrm{H}), 4.32(\mathrm{t}, J=3.60 \mathrm{~Hz}$, 2H), $4.06(\mathrm{t}, J=3.60 \mathrm{~Hz}, 2 \mathrm{H}), 2.34(\mathrm{~s}, 3 \mathrm{H})$.

1.2.17. N-(4-(6,7-Dimethoxy-3,4-dihydroisoquinolin-2(1H)-yl)butyl)-2-(2-hydroxyethoxy)-5methylbenzamide (23a) and N-(6-(6,7-dimethoxy-3,4-dihydroisoquinolin-2(1H)-yl)hexyl)-2-(2hydroxyethoxy)-5-methylbenzamide (23b)

DCC (58.9 mg, $0.29 \mathrm{mmol})$ and HOBt $(38.5 \mathrm{mg}, 0.29 \mathrm{mmol})$ were added to a solution of compound 22 (100 mg, $0.34 \mathrm{mmol}$ ) and 11a (or 11b) (0.29 mmol) in $\mathrm{CH}_{2} \mathrm{Cl}_{2}$ (3.70 mL). The reaction mixture was stirred at ambient temperature for $20 \mathrm{~h} . \quad \mathrm{H}_{2} \mathrm{O}(50.0 \mathrm{~mL})$ was added to the reaction mixture, and the mixture was extracted with EtOAc $(2$ x $30 \mathrm{~mL})$, washed with brine, and the combined organic layer was dried over anhydrous $\mathrm{Na}_{2} \mathrm{SO}_{4}$ and concentrated in vacuo. 
Flash column chromatography (10:1 $\left.\mathrm{CH}_{2} \mathrm{Cl}_{2}-\mathrm{MeOH}\right)$ gave compound 23a (115.2 mg, 34.5\%) as a white solid. ${ }^{1} \mathrm{H} \mathrm{NMR}\left(\mathrm{CDCl}_{3}\right) \delta 8.35(\mathrm{br}, \mathrm{NH}), 7.95(\mathrm{~d}, J=2.16 \mathrm{~Hz}, 1 \mathrm{H}), 7.17(\mathrm{~d}, J=3.60$ $\mathrm{Hz}, 1 \mathrm{H}), 6.82(\mathrm{~d}, J=7.20 \mathrm{~Hz}, 1 \mathrm{H}), 6.61(\mathrm{~s}, 1 \mathrm{H}), 6.50(\mathrm{~s}, 1 \mathrm{H}), 4.10(\mathrm{t}, J=3.60 \mathrm{~Hz}, 2 \mathrm{H}), 3.85(\mathrm{~s}$, 3H), $3.83(\mathrm{~s}, 3 \mathrm{H}), 3.81(\mathrm{t}, J=3.60 \mathrm{~Hz}, 2 \mathrm{H}), 3.71(\mathrm{~s}, 2 \mathrm{H}), 3.58-3.53(\mathrm{~m}, 2 \mathrm{H}), 2.91(\mathrm{~s}, 4 \mathrm{H}), 2.67(\mathrm{t}$, $J=7.20 \mathrm{~Hz}, 2 \mathrm{H}), 2.31(\mathrm{~s}, 3 \mathrm{H}), 1.92-1.84(\mathrm{~m}, 2 \mathrm{H}), 1.76-1.71(\mathrm{~m}, 2 \mathrm{H})$

Flash column chromatography (10:1 $\left.\mathrm{CH}_{2} \mathrm{Cl}_{2}-\mathrm{MeOH}\right)$ gave compound $23 \mathbf{b}(49.0 \mathrm{mg}, 36.5 \%)$ as a white solid. ${ }^{1} \mathrm{H} \mathrm{NMR}\left(\mathrm{CDCl}_{3}\right) \delta 8.26(\mathrm{br}, \mathrm{NH}), 7.96(\mathrm{~d}, J=2.16 \mathrm{~Hz}, 1 \mathrm{H}), 7.18(\mathrm{~d}, J=10.4$ $\mathrm{Hz}, 1 \mathrm{H}), 6.81(\mathrm{~d}, J=8.28,1 \mathrm{H}), 6.60(\mathrm{~s}, 1 \mathrm{H}), 6.50(\mathrm{~s}, 1 \mathrm{H}), 4.09(\mathrm{t}, J=4.50 \mathrm{~Hz}, 2 \mathrm{H}), 3.85(\mathrm{~s}, 3 \mathrm{H})$, $3.84(\mathrm{~s}, 3 \mathrm{H}), 3.81(\mathrm{t}, J=4.70 \mathrm{~Hz}, 2 \mathrm{H}), 3.74(\mathrm{~s}, 2 \mathrm{H}), 3.50-3.45(\mathrm{~m}, 2 \mathrm{H}), 2.93(\mathrm{~s}, 4 \mathrm{H}), 2.67(\mathrm{~s}, 2 \mathrm{H})$, $2.31(\mathrm{~s}, 3 \mathrm{H}), 1.76-1.62(\mathrm{~m}, 4 \mathrm{H}), 1.47-1.45(\mathrm{~m}, 4 \mathrm{H})$.

\subsubsection{2-(2-((4-(6,7-Dimethoxy-3,4-dihydroisoquinolin-2(1H)-yl)butyl)carbamoyl)-4-}

methylphenoxy)ethyl methanesulfonate (24a) and 2-(2-((6-(6,7-dimethoxy-3,4dihydroisoquinolin-2(1H)-yl)hexyl)carbamoyl)-4-methylphenoxy)ethyl methanesulfonate (24b)

$\mathrm{Et}_{3} \mathrm{~N}(43.5 \mu \mathrm{L}, 0.31 \mathrm{mmol})$ was slowly added to a solution of compound 23a (or $\left.23 \mathbf{b}\right)(0.10$ mmol) in $\mathrm{CH}_{2} \mathrm{Cl}_{2}(2.00 \mathrm{~mL})$ at $0{ }^{\circ} \mathrm{C}$. Methanesulfonyl chloride $(15.5 \mu \mathrm{L}, 0.20 \mathrm{mmol})$ was added and the reaction mixture was stirred at ambient temperature for $3 \mathrm{~h}$. The reaction mixture was diluted with $\mathrm{CH}_{2} \mathrm{Cl}_{2}(20.0 \mathrm{~mL})$, washed with $\mathrm{H}_{2} \mathrm{O}(2 \times 30.0 \mathrm{~mL})$, and the combined organic layer was dried over anhydrous $\mathrm{Na}_{2} \mathrm{SO}_{4}$ and concentrated in vacuo.

Flash column chromatography (15:1 $\left.\mathrm{CH}_{2} \mathrm{Cl}_{2}-\mathrm{MeOH}\right)$ gave compound $\mathbf{2 4 a}(45.8 \mathrm{mg}, 88 \%)$ [36] as a pale yellow solid. ${ }^{1} \mathrm{H}$ NMR $\left(\mathrm{CDCl}_{3}\right) \delta 8.20(\mathrm{~s}, 1 \mathrm{H}), 8.19(\mathrm{~s}, 1 \mathrm{H}), 7.55(\mathrm{~d}, J=18.0 \mathrm{~Hz}$, 
$1 \mathrm{H}), 7.17(\mathrm{~d}, J=5.40 \mathrm{~Hz}, 1 \mathrm{H}), 6.95(\mathrm{~s}, 1 \mathrm{H}), 6.88(\mathrm{~s}, 1 \mathrm{H}), 4.96(\mathrm{t}, J=3.60 \mathrm{~Hz}, 2 \mathrm{H}), 4.64(\mathrm{t}, J=$ 14.4 Hz, 2H), $4.22(\mathrm{~s}, 3 \mathrm{H}), 4.20(\mathrm{~s}, 3 \mathrm{H}), 4.00-3.80(\mathrm{~m}, 4 \mathrm{H}), 3.40-3.39(\mathrm{~m}, 3 \mathrm{H}), 3.20-3.08$ (m, 4H), 3.00-2.80 (m, 2H), $2.71(\mathrm{~s}, 3 \mathrm{H}), 2.10-2.07(\mathrm{~m}, 4 \mathrm{H})$.

Flash column chromatography $\left(15: 1 \mathrm{CH}_{2} \mathrm{Cl}_{2}-\mathrm{MeOH}\right)$ gave compound $\mathbf{2 4 b}(30.0 \mathrm{mg}, 52.6 \%)$ as a pale yellow solid. mp 61.7-62.0 ${ }^{\circ} \mathrm{C} .{ }^{1} \mathrm{H} \mathrm{NMR}\left(\mathrm{CDCl}_{3}\right) \delta 7.99(\mathrm{~d}, J=6.84 \mathrm{~Hz}, 1 \mathrm{H}), 7.78(\mathrm{br}$, NH), $7.22(\mathrm{~d}, J=7.20 \mathrm{~Hz}, 1 \mathrm{H}), 6.81(\mathrm{~d}, J=7.20 \mathrm{~Hz}, 1 \mathrm{H}), 6.60(\mathrm{~s}, 1 \mathrm{H}), 6.53(\mathrm{~s}, 1 \mathrm{H}), 4.65(\mathrm{t}, J=$ $5.40 \mathrm{~Hz}, 2 \mathrm{H}), 4.35(\mathrm{t}, J=5.40 \mathrm{~Hz}, 2 \mathrm{H}), 3.84(\mathrm{~s}, 3 \mathrm{H}), 3.83(\mathrm{~s}, 3 \mathrm{H}), 3.49-3.43(\mathrm{~m}, 2 \mathrm{H}), 3.08(\mathrm{~s}$, 2H), 2.32 (s, 3H), 1.61-1.44 (m, 14H). LCMS m/z 549.2131 (M+H). HRMS (ESI) (M+H) calcd for $\mathrm{C}_{28} \mathrm{H}_{41} \mathrm{~N}_{2} \mathrm{O}_{7} \mathrm{~S}, 549.2634$; found, 549.2620.

\subsection{In vitro sigma binding assays}

The test compounds were dissolved in DMSO or ethanol and then diluted in $50 \mathrm{mM}$ Tris-HCl buffer containing $150 \mathrm{mM} \mathrm{NaCl}$ and $100 \mathrm{mM}$ EDTA at $\mathrm{pH} 7.4$ prior to performing the $\sigma_{1}$ and $\sigma_{2}$ receptor binding assays. Briefly, the $\sigma_{1}$ receptor binding assays were conducted in 96-well plates using guinea pig brain membrane homogenates $\left(\sim 300 \mu\right.$ g protein) and $6 \mathrm{nM}\left[{ }^{3} \mathrm{H}\right](+)$-pentazocine $(\sim 42,000 \mathrm{cpm}$, Perkin-Elmer, Boston, MA). The total incubation time was $120 \mathrm{~min}$ at room temperature. Non-specific binding was determined from samples that contained $10 \mu \mathrm{M}$ of cold haloperidol. After $120 \mathrm{~min}$, the reaction was terminated by the addition of $150 \mu \mathrm{L}$ of ice-cold wash buffer (10 mM Tris- $\mathrm{HCl}, 150 \mathrm{mM} \mathrm{NaCl}, \mathrm{pH} 7.4)$ using a 96 channel transferring pipet (Fisher Scientific, Pittsburgh, PA). The samples were harvested and filtered rapidly through a 96well fiberglass filter plate (Millipore, Billerica, MA) that had been pre-soaked with $100 \mu \mathrm{L}$ of 50 $\mathrm{mM}$ Tris- $\mathrm{HCl}$ buffer at $\mathrm{pH} 8.0$ for $1 \mathrm{~h}$. Each filter was washed three times with $200 \mu \mathrm{L}$ of ice- 
cold wash buffer, and the filter was counted. The $\sigma_{2}$ receptor binding assays were conducted using rat liver membrane homogenates $\left(\sim 300 \mu \mathrm{g}\right.$ protein) and $5 \mathrm{nM}\left[{ }^{3} \mathrm{H}\right] \mathrm{DTG}(\sim 82,000 \mathrm{cpm}$, Perkin-Elmer, Boston, MA) in the presence of $100 \mathrm{nM}(+)$-pentazocine to block $\sigma_{1}$ sites. The incubation time was $120 \mathrm{~min}$ at room temperature. Non-specific binding was determined from samples that contained $5 \mu \mathrm{M}$ of cold DTG. All other procedures were identical to those described for the $\sigma_{1}$ receptor binding assay above. Data from the competitive inhibition experiments were modeled using nonlinear regression analysis to determine the concentration that inhibits $50 \%$ of the specific binding of the radioligand $\left(I C_{50}\right.$ value). $K_{\mathrm{i}}$ values were calculated using the reported method [44] and are presented as the mean \pm SEM. For these calculations, we used a $K_{\mathrm{d}}$ value of $7.89 \mathrm{nM}$ for $\left[{ }^{3} \mathrm{H}\right](+)$-pentazocine and guinea pig brain. For $\left[{ }^{3} \mathrm{H}\right] \mathrm{DTG}$ and rat liver, we used $30.73 \mathrm{nM}[38]$.

\subsection{Radiochemical Synthesis of $\left[{ }^{18} \mathrm{~F}\right] 3$ and $\left[{ }^{18} \mathrm{~F}\right] 7$}

$\left[{ }^{18}\right.$ F]Fluoride $(1.8-2.0 \mathrm{GBq})$ was trapped on a Sep-pak ${ }^{\circledR}$ QMA-bicarb cartridge from the cyclotron, and eluted to the reaction vial using $7.0 \mathrm{mg}$ of Kryptofix 222 and $3.0 \mathrm{mg}$ of $\mathrm{K}_{2} \mathrm{CO}_{3}$ solution. Three azeotropic distillations were then performed using $0.5-1.0 \mathrm{~mL}$ aliquots of anhydrous acetonitrile at $100{ }^{\circ} \mathrm{C}$ (oil bath) under a gentle stream of $\mathrm{N}_{2}$. The precursor $24 \mathrm{a}$ (or 24b) $(1.5 \mathrm{mg})$ in DMSO $(200 \mu \mathrm{L})$ was added to the resulting $\mathrm{K}\left[{ }^{18} \mathrm{~F}\right] \mathrm{F}$ in the reaction vial. The reaction mixture was heated at $120^{\circ} \mathrm{C}$ for $15 \mathrm{~min}$ (Scheme 4). At the end of the reaction, $1.5 \mathrm{~mL}$ of the HPLC mobile phase was added to the reaction vial, after passing through Sep-pak ${ }^{\circledR}$ Alumina light cartridge, the crude product was then purified by HPLC using a semi-preparative column eluted with a 45:55 mixture of methanol and 0.1 $\mathrm{M}$ ammonium formate (aq) at a flow 
rate of $5 \mathrm{~mL} / \mathrm{min}$ for $\left[{ }^{18} \mathrm{~F}\right] 3$ or with a $46: 54$ mixture of methanol and $0.1 \mathrm{M}$ aqueous ammonium formate at a flow rate of $5 \mathrm{~mL} / \mathrm{min}$ for $\left[{ }^{18} \mathrm{~F}\right] 7$. The desired products eluted between 29 and 30 min for $\left[{ }^{18} \mathrm{~F}\right] 3$ and between 27 and 28 min for $\left[{ }^{18} \mathrm{~F}\right] 7$. The collected products were diluted with $30 \mathrm{~mL}$ of $\mathrm{H}_{2} \mathrm{O}$, trapped Sep-pak ${ }^{\circledR} \mathrm{C}-18$ plus cartridge, and formulated $10 \% \mathrm{EtOH}$-saline for the in vivo biodistribution study or microPET imaging study. Specific activity was determined by comparing the UV peak area of the desired radioactive peak and the UV peak areas of different concentrations of unlabeled standard $\mathbf{3}$ or $\mathbf{7}$ on HPLC. Identification of radioligand $\left[{ }^{18} \mathrm{~F}\right] \mathbf{3}$ and $\left[{ }^{18} \mathrm{~F}\right] 7$ was determined by co-injecting the radioligand with the corresponding unlabeled standard into the HPLC system.

\subsection{Cellular uptake and blocking study of $\left[{ }^{18} \mathrm{~F}\right] 7$ in EMT6 Cells}

EMT6 (mouse mammary carcinoma) cells were cultured at $37{ }^{\circ} \mathrm{C}$ under $5 \% \mathrm{CO}_{2}$ in $85 \%$ Waymouth's MB 752/1 Medium with 2 mM L-glutamine containing 15\% FBS. EMT6 cells (5.0 X $10^{4}$ cells/well) were plated prior to ligand incubation within a 96 well plate. Radiotracer $\left[{ }^{18} \mathrm{~F}\right] 7$ $\left(\sim 1,000,000 \mathrm{cpm} / 50 \mu \mathrm{L} /\right.$ well) was dissolved in PBS $\left(\mathrm{w} / \mathrm{Ca}^{2+}\right.$ and $\mathrm{Mg}^{2+}$ ) and incubated with EMT6 cells at $37^{\circ} \mathrm{C}$ for $1,2,3,5,10,20,30,45,60,90$ and $120 \mathrm{~min}(\mathrm{n}=3)$. Cells were then washed twice with ice cold PBS (w/Ca ${ }^{2+}$ and $\mathrm{Mg}^{2+}$ ), lysed cells using $200 \mu \mathrm{L}$ of $1 \mathrm{~N} \mathrm{NaOH}$, and counted. To investigate the blocking of $\left[{ }^{18} \mathrm{~F}\right] 7$ uptake by RHM-4, EMT6 cells were incubated with $\left[{ }^{18} \mathrm{~F}\right] 7(\sim 1,000,000 \mathrm{cpm} / 25 \mu \mathrm{l} /$ well $)$ in the presence of $100 \mu \mathrm{M}$ RHM-4 $(25 \mu \mathrm{l}$ in PBS $)$ at $37{ }^{\circ} \mathrm{C}$ for same time point as above. Cells were then washed as described above and counted. 


\subsection{In vivo biodistribution studies of $\left[{ }^{18} \mathrm{~F}\right] 7$}

EMT6 mammary carcinoma cells were injected into the right flanks of female Balb/C mice. Experiments were conducted when tumors had reached a diameter of between 1.0 and $1.2 \mathrm{~cm}$. Radioligand $\left[{ }^{18} \mathrm{~F}\right] 7(1.11 \mathrm{MBq})$ in $0.15 \mathrm{~mL}$ of $10 \% \mathrm{EtOH}$-saline was injected into mice via a tail vein. At 5, 60, and 120 min postinjection, the mice $(n=4)$ were sacrificed, and blood, heart, muscle, lung, kidney, pancreas, spleen, liver, brain, bone, and tumor removed, weighed and counted. Data are expressed as a percent injected dose per gram of tissue (\%ID/g).

\subsection{MicroPET imaging of $\left[{ }^{18} \mathrm{~F}\right] 3$ and $\left[{ }^{18} \mathrm{~F}\right] 7$}

MicroPET imaging was performed on a Philips Mosaic small animal scanner, which has 2 $\mathrm{mm}$ spatial resolution, with high sensitivity and transverse imaging field-of-view of $12.8 \mathrm{~cm}$. Two weeks after inoculation with EMT6 mammary carcinoma cells, mice with a tumor size of 1 1.2 $\mathrm{cm}$ underwent microPET imaging. Mice were anesthetized with isoflurane, which was maintained via nosecone, and placed on a heating pad on the scanner bed. The dynamic images of these mice were acquired for $2 \mathrm{~h}$ after injection of $\left[{ }^{18} \mathrm{~F}\right] 3$ (or $\left[{ }^{18} \mathrm{~F}\right] 7,10-11 \mathrm{MBq}$ ) in $0.15 \mathrm{~mL}$ of $10 \%$ EtOH-saline solution. Elipsoid VOIs were drawn around the tumor $(5 \times 4 \times 4 \mathrm{~mm})$ and muscle ( $3 \times 3 \times 4 \mathrm{~mm})$ regions. Biceps brachii muscle (left flank) was used as the reference region. Time activity curves of the tumor regions and the muscle regions were obtained from mean counts/voxel of each VOI by Amide software.

\section{Results and discussion}




\subsection{Chemistry}

Compounds 3 and 7 were synthesized from compounds 11 and $\mathbf{1 3}$ using a condensation reaction between benzoic acid and amine. Compound $\mathbf{1 3}$ was synthesized from methyl 5methylsalicylate and 2-fluoroethyl 4-methylbenzenesulfonate in 2 steps, and compounds $\mathbf{1 1 a}$ and 11b were prepared using phthalimide as a protecting group in 2 steps (Scheme 1). Synthetic pathways of eight novel indole- and benzothiophene-substituted tetrahydroisoquinoline analogues, 8a-8d and 9a-9d (Figure 2), are shown in Schemes 2-3. These analogues were synthesized by condensation of 11a (or 11b) and the corresponding carboxylic acid, 5-methoxy$1 H$-indole-2-carboxylic acid and $\mathbf{1 5}$ for indole-substituted analogues, or $\mathbf{1 7}$ and $\mathbf{2 0}$ for benzothiophene-substituted analogues in the presence of $\mathrm{HOBt}$ and $\mathrm{DCC}$ in $\mathrm{CH}_{2} \mathrm{Cl}_{2}$. Compounds 15, 17, and 20 were hydrolyzed from the corresponding carboxylate, 14, 16, and 19 in the presence of solid $\mathrm{NaOH}$ in $\mathrm{MeOH} / \mathrm{H}_{2} \mathrm{O}$. Benzothiophene moieties, 16 and 19, were cyclized between 2-fluoro-5-methoxybenzaldehyde (or 18) and methyl thioglycolate as a sulfur source in the presence of $\mathrm{NaH}$ in DMSO and DMF, respectively. Compounds $\mathbf{1 4}$ and $\mathbf{1 8}$ were prepared from ethyl 5-hydroxy-1H-indole-2-carboxylate or 5-hydroxy-2-nitrobenzaldehyde with 2fluoroethyl 4-methylbenzenesulfonate in the presence of $\mathrm{K}_{2} \mathrm{CO}_{3}$ in high yields (64.6-99\%). For the comparison 4 and 6-carbon spacer analogues, $\left[{ }^{18} \mathrm{~F}\right] \mathbf{3}$ and $\left[{ }^{18} \mathrm{~F}\right] \mathbf{7}$ were radiolabeled from $24 a$ and 24b with ${ }^{18} \mathrm{~F}$, as shown in Scheme 4. Alkylation of the ortho-hydroxyl group of methyl 2hydroxy-5-methylbenzoate with 1-bromoethyl acetate, followed by hydrolysis of the acetate group produced 22. Compounds 23a and 23b were then converted to the corresponding mesylates, 24a and $\mathbf{2 4 b}$, by treatment with methanesulfonyl chloride in dichloromethane using $\mathrm{Et}_{3} \mathrm{~N}$ as an acid scavenger (Scheme 4). 


\subsection{In vitro sigma binding assays}

The results of the binding assays for compounds $\mathbf{3}$ and $\mathbf{7}$, along with haloperidol and DTG as standard controls are shown in Table 1. Haloperidol (3.18 and $57.9 \mathrm{nM}$ for $\sigma_{1}$ and $\sigma_{2}$ receptors, respectively) and DTG (59.9 and $19.4 \mathrm{nM}$ for $\sigma_{1}$ and $\sigma_{2}$ receptors, respectively) showed similar $K_{i}$ values to previously reported data. The binding affinities of compound $\mathbf{3}$ and $\mathbf{7}$ for the $\sigma_{1}$ receptor were 95.1 and over $1000 \mathrm{nM}$, and for the $\sigma_{2}$ receptors were 13.3 and $23.1 \mathrm{nM}$, respectively. The $\sigma_{1}: \sigma_{2}$ ratios of compound $\mathbf{3}$ and 7 were 7.15 and over 43.3 . These results indicate that although compound $\mathbf{7}$ had a lower affinity for $\sigma_{2}$ receptors versus compound $\mathbf{3}$, it had a higher selectivity ratio value for the $\sigma_{2}$ versus $\sigma_{1}$ receptor. $K_{i}$ values of indole and benzothiophene derivatives, $\mathbf{8 a - 9 d}$, for $\sigma_{2}$ receptors were desirable, ranging from 18.2 to $37.9 \mathrm{nM}$ as well as they showed high selective binding to $\sigma_{2}$ receptors compare to $\sigma_{1}$ receptors $\left(\sigma_{2}: \sigma_{1}=\right.$ 17.4-215.5) (Table 1). In terms of selectivity for $\sigma_{2}$ receptors to $\sigma_{1}$ receptors, 4-carbon spacer derivatives showed higher selectivity than the corresponding 6-carbon spacer derivatives in both analogues.

\subsection{Radiochemical synthesis of $\left[{ }^{18} \mathrm{~F}\right] 3$ and $\left[{ }^{18} \mathrm{~F}\right] 7$}

$\left[{ }^{18} \mathrm{~F}\right] \mathbf{3}$ and $\left[{ }^{18} \mathrm{~F}\right] \mathbf{7}$ were synthesized from mesylate precursors, $\mathbf{2 4 a}$ and $\mathbf{2 4 b}$, with $\left[{ }^{18} \mathrm{~F}\right]$ fluoride/ $\mathrm{K}_{2} \mathrm{CO}_{3}$ and Kryptofix 222, using DMSO as the solvent (Scheme 4). The following HPLC purification gave $\left[{ }^{18} \mathrm{~F}\right] 3$ and $\left[{ }^{18} \mathrm{~F}\right] 7$ in an overall $15-40 \%$ decay-corrected radiochemical yield and radiochemical purity higher than $99 \%$ with specific activity of 70 and $73 \mathrm{GBq} / \mu \mathrm{mol}$. The total synthesis time including HPLC purification was $2 \mathrm{~h}$. 


\subsection{Cellular uptake and blocking study of $\left[{ }^{18} \mathrm{~F}\right] 7$ in EMT6 Cells}

The uptake of $\left[{ }^{18} \mathrm{~F}\right] 7$ in EMT6 cells increased from $18 \%$ uptake/100 $\mu \mathrm{g}$ protein at 0 min to $30 \%$ uptake $/ 100 \mu \mathrm{g}$ protein at $20 \mathrm{~min}$; the uptake then remained level from $20 \mathrm{~min}$ to $120 \mathrm{~min}$. (25\% $30 \%$ uptake/100 $\mu \mathrm{g}$ protein). The uptake of $\left[{ }^{18} \mathrm{~F}\right] 7$ in EMT6 cells was reduced by co-incubation of $100 \mu \mathrm{M}$ of the $\sigma_{2}$ receptor antagonist, RHM-4 [36, 45]; that is, the cell uptake in the blocking study ranged from 5 to $10 \%$ uptake/100 $\mu$ g protein, which represents a $70-80 \%$ reduction in uptake relative to the control group (Figure 3). This result demonstrated that $\left[{ }^{18} \mathrm{~F}\right] 7$ specifically binds to $\sigma_{2}$ receptors in the EMT6 breast cancer cells.

\subsection{In vivo biodistribution of $\left[{ }^{18} \mathrm{~F}\right] 7$ and microPET imaging studies of of $\left[{ }^{18} \mathrm{~F}\right] 3$ and $\left[{ }^{18} \mathrm{~F}\right] 7$}

The results of the biodistribution studies of $\left[{ }^{18} \mathrm{~F}\right] 7$ in female Balb/c mice bearing EMT-6 tumors are shown in Table 2. $\left[{ }^{18} \mathrm{~F}\right] 7$ displayed a modest tumor uptake 0.52 of the injected dose per gram $(\% \mathrm{ID} / \mathrm{g})$ at $5 \mathrm{~min}$ post-injection and the tumor uptake increased $(1.55 \% \mathrm{ID} / \mathrm{g}$, respectively) at $1 \mathrm{~h}$ post-injection and at $2 \mathrm{~h}$ post-injection $(1.19 \% \mathrm{ID} / \mathrm{g})$ in mice. The tumor uptake of $\left[{ }^{18} \mathrm{~F}\right] 7$ at $1 \mathrm{~h}$ and $2 \mathrm{~h}$ post-injection is higher than the reported values of $\left[{ }^{18} \mathrm{~F}\right] \mathbf{3}$ (i.e., $\left.\left[{ }^{18} \mathrm{~F}\right] \mathrm{ISO}-1\right)$ at $1 \mathrm{~h}(1.14 \% \mathrm{ID} / \mathrm{g})$ and at $2 \mathrm{~h}(0.64 \% \mathrm{ID} / \mathrm{g})$ post-injection [36] in mice. $\left[{ }^{18} \mathrm{~F}\right] 7$ also had good tumor : muscle (left flank) ratios at $1 \mathrm{~h} \mathrm{(2.92)}$ and $2 \mathrm{~h}$ (3.30) post-injection of the radiotracer. Low bone uptake of $\left[{ }^{18} \mathrm{~F}\right] 7$ was observed (Table 2), suggesting that it does not undergo in vivo metabolic defluorination.

MicroPET imaging studies comparing both $\left[{ }^{18} \mathrm{~F}\right] \mathbf{3}$ (i.e., $\left.\left[{ }^{18} \mathrm{~F}\right] \mathrm{ISO}-1\right)$ and $\left[{ }^{18} \mathrm{~F}\right] 7$ were conducted in tumor-bearing mice. The EMT-6 tumors were readily identifiable using both radioligands (Figure 4). $\left[{ }^{18} \mathrm{~F}\right] 7$ showed higher tumor uptake and higher tumor: muscle ratios than $\left[{ }^{18} \mathrm{~F}\right] \mathbf{3}$ in the 
images (Figure 5). These results suggest that $\left[{ }^{18} \mathrm{~F}\right] 7$ may be a suitable PET probe for imaging $\sigma_{2}$ receptor in vivo with PET.

\section{Conclusions}

In this study, we synthesized nine novel $\sigma_{2}$ ligands including a 6-carbon spacer analogue of ISO-1, four indole analogues, and four benzothiophene analogues which have moderate binding affinity and high selectivity for $\sigma_{2}$ versus $\sigma_{1}$ receptors (Table 1 ). $\left[{ }^{18} \mathrm{~F}\right] 7$ was also successfully radiolabeled with ${ }^{18} \mathrm{~F}$ and evaluated as a potential radiotracer for imaging EMT-6 tumors in female Balb/c mice. Although $\left[{ }^{18} \mathrm{~F}\right] 7$ has a lower binding affinity for $\sigma_{2}$ receptors than $\left[{ }^{18} \mathrm{~F}\right] \mathbf{3}$ in vitro, it displays a high tumor uptake and suitable tumor: muscle ratios for imaging studies. MicroPET studies demonstrated $\left[{ }^{18} \mathrm{~F}\right] 7$ had a higher tumor uptake and a higher tumor : muscle ratio than that of $\left[{ }^{18} \mathrm{~F}\right] \mathbf{3}$. Therefore, the 6-carbon spacer analogue of ISO-1 $\left(\left[{ }^{18} \mathrm{~F}\right] 7\right)$ may be a useful probe for detecting solid tumors and imaging their $\sigma_{2}$ receptors status with PET. In contrast to previous suggestions, we observed no difference in $\sigma_{2}$ receptor binding affinity between the 4-carbon and 6-carbon linker within the indole and benzothiophene series.

\section{Acknowledgements}

This research was supported by DOE Training Grant DE-SC0012476 (D.A. Mankoff, P.I.) 


\section{References}

[1] Martin WR, Eades CG, Thompson JA, Huppler RE, and Gilbert PE. The effects of morphineand nalorphine- like drugs in the nondependent and morphine-dependent chronic spinal dog. The Journal of pharmacology and experimental therapeutics 1976;197:517-32.

[2] Tam SW and Cook L. Sigma opiates and certain antipsychotic drugs mutually inhibit (+)-[3H] SKF 10,047 and [3H]haloperidol binding in guinea pig brain membranes. Proc Natl Acad Sci U S A 1984;81:5618-21.

[3] Walker JM, Bowen WD, Walker FO, Matsumoto RR, De Costa B, and Rice KC. Sigma receptors: biology and function. Pharmacol Rev 1990;42:355-402.

[4] Hellewell SB and Bowen WD. A sigma-like binding site in rat pheochromocytoma (PC12) cells: decreased affinity for (+)-benzomorphans and lower molecular weight suggest a different sigma receptor form from that of guinea pig brain. Brain Res 1990;527:244-53.

[5] Quirion R, Bowen WD, Itzhak Y, Junien JL, Musacchio JM, Rothman RB, et al. A proposal for the classification of sigma binding sites. Trends Pharmacol Sci 1992;13:85-6.

[6] Guitart X, Codony X, and Monroy X. Sigma receptors: biology and therapeutic potential. Psychopharmacology (Berl) 2004;174:301-19.

[7] Hanner M, Moebius FF, Flandorfer A, Knaus HG, Striessnig J, Kempner E, et al. Purification, molecular cloning, and expression of the mammalian sigma1-binding site. Proc Natl Acad Sci U S A 1996;93:8072-7. 
[8] Xu J, Zeng C, Chu W, Pan F, Rothfuss JM, Zhang F, et al. Identification of the PGRMC1 protein complex as the putative sigma-2 receptor binding site. Nature communications 2011;2:380.

[9] Abate C, Niso M, Infantino V, Menga A, and Berardi F. Elements in support of the "nonidentity' of the PGRMC1 protein with the $\sigma 2$ receptor. European journal of pharmacology 2015;758:16-23.

[10] Chu UB, Mavlyutov TA, Chu M-L, Yang H, Schulman A, Mesangeau C, et al. The Sigma-2 Receptor and Progesterone Receptor Membrane Component 1 are Different Binding Sites Derived From Independent Genes. EBioMedicine 2015;2:1806-13.

[11] Crawford KW and Bowen WD. Sigma-2 receptor agonists activate a novel apoptotic pathway and potentiate antineoplastic drugs in breast tumor cell lines. Cancer research 2002;62:313-22.

[12] Vilner BJ, John CS, and Bowen WD. Sigma-1 and sigma-2 receptors are expressed in a wide variety of human and rodent tumor cell lines. Cancer research 1995;55:408-13.

[13] van Waarde A, Rybczynska AA, Ramakrishnan N, Ishiwata K, Elsinga PH, and Dierckx RA. Sigma receptors in oncology: therapeutic and diagnostic applications of sigma ligands. Curr Pharm Des 2010;16:3519-37.

[14] Hornick JR, Xu J, Vangveravong S, Tu Z, Mitchem JB, Spitzer D, et al. The novel sigma-2 receptor ligand SW43 stabilizes pancreas cancer progression in combination with gemcitabine. Molecular cancer 2010;9:298. 
[15] Mach RH, Smith CR, al-Nabulsi I, Whirrett BR, Childers SR, and Wheeler KT. Sigma 2 receptors as potential biomarkers of proliferation in breast cancer. Cancer research 1997;57:15661.

[16] Barg J, Thomas GE, Bem WT, Parnes MD, Ho AM, Belcheva MM, et al. In vitro and in vivo expression of opioid and sigma receptors in rat C6 glioma and mouse N18TG2 neuroblastoma cells. Journal of neurochemistry 1994;63:570-4.

[17] Colabufo NA, Berardi F, Contino M, Ferorelli S, Niso M, Perrone R, et al. Correlation between sigma 2 receptor protein expression and histopathologic grade in human bladder cancer. Cancer Lett 2006;237:83-8.

[18] Azzariti A, Colabufo NA, Berardi F, Porcelli L, Niso M, Simone GM, et al. Cyclohexylpiperazine derivative PB28, a sigma2 agonist and sigma1 antagonist receptor, inhibits cell growth, modulates P-glycoprotein, and synergizes with anthracyclines in breast cancer. Molecular cancer therapeutics 2006;5:1807-16.

[19] Kashiwagi H, McDunn JE, Simon PO, Jr., Goedegebuure PS, Xu J, Jones L, et al. Selective sigma-2 ligands preferentially bind to pancreatic adenocarcinomas: Applications in diagnostic imaging and therapy. Mol Cancer 2007;6:48.

[20] Peluso JJ, Liu X, Saunders MM, Claffey KP, and Phoenix K. Regulation of ovarian cancer cell viability and sensitivity to cisplatin by progesterone receptor membrane component-1. J Clin Endocrinol Metab 2008;93:1592-9. 
[21] Kashiwagi H, McDunn JE, Simon PO, Jr., Goedegebuure PS, Vangveravong S, Chang K, et al. Sigma-2 receptor ligands potentiate conventional chemotherapies and improve survival in models of pancreatic adenocarcinoma. J Transl Med 2009;7:24.

[22] Hornick JR, Spitzer D, Goedegebuure P, Mach RH, and Hawkins WG. Therapeutic targeting of pancreatic cancer utilizing sigma-2 ligands. Surgery 2012;152:S152-6.

[23] Wheeler KT, Wang LM, Wallen CA, Childers SR, Cline JM, Keng PC, et al. Sigma-2 receptors as a biomarker of proliferation in solid tumours. Br J Cancer 2000;82:1223-32.

[24] Al-Nabulsi I, Mach RH, Wang LM, Wallen CA, Keng PC, Sten K, et al. Effect of ploidy, recruitment, environmental factors, and tamoxifen treatment on the expression of sigma-2 receptors in proliferating and quiescent tumour cells. British journal of cancer 1999;81:925-33.

[25] Zeng C, Vangveravong S, Xu J, Chang KC, Hotchkiss RS, Wheeler KT, et al. Subcellular localization of sigma-2 receptors in breast cancer cells using two-photon and confocal microscopy. Cancer research 2007;67:6708-16.

[26] Ostenfeld MS, Fehrenbacher N, Hoyer-Hansen M, Thomsen C, Farkas T, and Jaattela M. Effective tumor cell death by sigma-2 receptor ligand siramesine involves lysosomal leakage and oxidative stress. Cancer research 2005;65:8975-83.

[27] Rybczynska AA, Dierckx RA, Ishiwata K, Elsinga PH, and van Waarde A. Cytotoxicity of sigma-receptor ligands is associated with major changes of cellular metabolism and complete occupancy of the sigma-2 subpopulation. Journal of nuclear medicine : official publication, Society of Nuclear Medicine 2008;49:2049-56. 
[28] Zeng C, Vangveravong S, McDunn JE, Hawkins WG, and Mach RH. Sigma-2 receptor ligand as a novel method for delivering a SMAC mimetic drug for treating ovarian cancer. Br $\mathrm{J}$ Cancer 2013;109:2368-77.

[29] Niso M, Abate C, Contino M, Ferorelli S, Azzariti A, Perrone R, et al. Sigma-2 receptor agonists as possible antitumor agents in resistant tumors: hints for collateral sensitivity. ChemMedChem 2013;8:2026-35.

[30] Shoghi KI, Xu J, Su Y, He J, Rowland D, Yan Y, et al. Quantitative receptor-based imaging of tumor proliferation with the sigma-2 ligand [(18)F]ISO-1. PLoS One 2013;8:e74188.

[31] Chen X, Cui MC, Deuther-Conrad W, Tu YF, Ma T, Xie Y, et al. Synthesis and biological evaluation of a novel 99mTc cyclopentadienyl tricarbonyl complex ([(Cp-R)99mTc(CO)3]) for sigma-2 receptor tumor imaging. Bioorganic \& medicinal chemistry letters 2012;22:6352-7.

[32] Mach RH, Dehdashti F, and Wheeler KT. PET Radiotracers for Imaging the Proliferative Status of Solid Tumors. PET clinics 2009;4:1-15.

[33] Hou C, Tu Z, Mach R, Kung HF, and Kung MP. Characterization of a novel iodinated sigma-2 receptor ligand as a cell proliferation marker. Nuclear medicine and biology 2006;33:203-9.

[34] Xu J, Tu Z, Jones LA, Vangveravong S, Wheeler KT, and Mach RH. [3H]N-[4-(3,4dihydro-6,7-dimethoxyisoquinolin-2(1H)-yl)butyl]-2-methoxy-5-methyl benzamide: a novel sigma-2 receptor probe. European journal of pharmacology 2005;525:8-17. 
[35] Rowland DJ, Lewis JS, and Welch MJ. Molecular imaging: the application of small animal positron emission tomography. J Cell Biochem Suppl 2002;39:110-5.

[36] Tu Z, Xu J, Jones LA, Li S, Dumstorff C, Vangveravong S, et al. Fluorine-18-labeled benzamide analogues for imaging the sigma2 receptor status of solid tumors with positron emission tomography. J Med Chem 2007;50:3194-204.

[37] Chu W, Xu J, Zhou D, Zhang F, Jones LA, Wheeler KT, et al. New N-substituted 9azabicyclo[3.3.1]nonan-3alpha-yl phenylcarbamate analogs as sigma2 receptor ligands: synthesis, in vitro characterization, and evaluation as PET imaging and chemosensitization agents. Bioorganic \& medicinal chemistry 2009;17:1222-31.

[38] Tu Z, Dence CS, Ponde DE, Jones L, Wheeler KT, Welch MJ, et al. Carbon-11 labeled sigma2 receptor ligands for imaging breast cancer. Nuclear medicine and biology 2005;32:42330.

[39] Bai S, Li S, Xu J, Peng X, Sai K, Chu W, et al. Synthesis and structure-activity relationship studies of conformationally flexible tetrahydroisoquinolinyl triazole carboxamide and triazole substituted benzamide analogues as sigma2 receptor ligands. J Med Chem 2014;57:4239-51.

[40] Ashford ME, Nguyen VH, Greguric I, Pham TQ, Keller PA, and Katsifis A. Synthesis and in vitro evaluation of tetrahydroisoquinolines with pendent aromatics as sigma-2 (sigma2) selective ligands. Organic \& biomolecular chemistry 2014;12:783-94.

[41] Dehdashti F, Laforest R, Gao F, Shoghi KI, Aft RL, Nussenbaum B, et al. Assessment of cellular proliferation in tumors by PET using 18F-ISO-1. Journal of nuclear medicine : official publication, Society of Nuclear Medicine 2013;54:350-7. 
[42] Hajipour AR, Guo L-W, Pal A, Mavlyutov T, and Ruoho AE. Electron-donating paramethoxy converts a benzamide-isoquinoline derivative into a highly Sigma-2 receptor selective ligand. Bioorganic \& medicinal chemistry 2011;19:7435-40.

[43] Bojarski AJ, Mokrosz MJ, Minol SC, Kozioł A, Wesołowska A, Tatarczyńska E, et al. The influence of substitution at aromatic part of 1,2,3,4-tetrahydroisoquinoline on in vitro and in vivo 5-HT1A/5-HT2A receptor activities of its 1-adamantoyloaminoalkyl derivatives. Bioorganic \& medicinal chemistry 2002;10:87-95.

[44] Cheng Y and Prusoff WH. Relationship between the inhibition constant (K1) and the concentration of inhibitor which causes 50 per cent inhibition (I50) of an enzymatic reaction. Biochemical pharmacology 1973;22:3099-108.

[45] Tu Z, Xu J, Jones LA, Li S, Zeng D, Kung MP, et al. Radiosynthesis and biological evaluation of a promising sigma(2)-receptor ligand radiolabeled with fluorine-18 or iodine-125 as a PET/SPECT probe for imaging breast cancer. Applied radiation and isotopes : including data, instrumentation and methods for use in agriculture, industry and medicine 2010;68:2268-73. 
Table 1. Binding affinity $\left(K_{i}\right)$ of compounds for the $\sigma_{1}$ and $\sigma_{2}$ receptors assayed in vitro.

\begin{tabular}{|c|c|c|c|c|}
\hline \multirow[b]{2}{*}{ Compound } & \multicolumn{4}{|c|}{$K_{i}$ value $(\mathrm{nM})$} \\
\hline & $\sigma_{1}$ & $\sigma_{2}$ & $\begin{array}{l}\sigma_{1}: \sigma_{2} \\
\text { ratio }\end{array}$ & $\begin{array}{c}C \log P^{a} \\
\text { (calculated })\end{array}$ \\
\hline Haloperidol & $3.18 \pm 0.04$ & $57.9 \pm 5.25$ & 0.05 & \\
\hline DTG & $59.9 \pm 1.45$ & $19.4 \pm 1.21$ & 3.08 & \\
\hline 3 (ISO-1) & $95.1 \pm 4.40$ & $13.3 \pm 1.00$ & 7.15 & $3.06 \pm 0.51$ \\
\hline 7 & $>1000$ & $23.1 \pm 1.34$ & $>43.3$ & $3.64 \pm 0.51$ \\
\hline $8 \mathbf{a}$ & $>5000$ & $23.2 \pm 5.55$ & $>215.5$ & $3.43 \pm 0.87$ \\
\hline $8 b$ & $>2000$ & $33.6 \pm 5.29$ & $>59.5$ & $4.19 \pm 0.87$ \\
\hline $8 c$ & $>2000$ & $24.0 \pm 4.13$ & $>83.3$ & $3.66 \pm 0.92$ \\
\hline 8d & $>2000$ & $37.9 \pm 1.16$ & $>52.7$ & $4.42 \pm 0.92$ \\
\hline $9 \mathbf{a}$ & $>2000$ & $25.6 \pm 2.21$ & $>78.1$ & $4.57 \pm 1.10$ \\
\hline $9 b$ & $>1000$ & $23.5 \pm 1.54$ & $>42.5$ & $5.33 \pm 1.10$ \\
\hline $9 c$ & $>2000$ & $21.3 \pm 1.22$ & $>93.8$ & $4.80 \pm 1.14$ \\
\hline 9d & $316 \pm 3.5$ & $18.2 \pm 1.13$ & 17.4 & $5.56 \pm 1.14$ \\
\hline
\end{tabular}

${ }^{a}$ Calculated using ACD log P software, Advanced Chemistry Development 
Table 2. In vivo biodistribution of $\left[{ }^{18} \mathrm{~F}\right] 7$ in female Balb/c mice bearing EMT-6 tumors

\begin{tabular}{cccc}
\hline & & $(\% \mathrm{ID} / \mathrm{g})(\mathrm{n}=4)$ & \\
\hline & $5 \mathrm{~min}$ & $60 \mathrm{~min}$ & $120 \mathrm{~min}$ \\
\hline Blood & $2.31 \pm 0.13$ & $1.65 \pm 0.14$ & $1.16 \pm 0.06$ \\
Heart & $3.21 \pm 1.55$ & $1.59 \pm 0.18$ & $0.85 \pm 0.05$ \\
Muscle & $0.57 \pm 0.11$ & $0.53 \pm 0.03$ & $0.36 \pm 0.07$ \\
Lung & $9.29 \pm 3.25$ & $2.63 \pm 0.32$ & $1.46 \pm 0.09$ \\
Kidney & $38.6 \pm 6.37$ & $5.59 \pm 0.69$ & $3.59 \pm 0.37$ \\
Pancreas & $8.78 \pm 1.82$ & $41.0 \pm 6.99$ & $25.9 \pm 5.43$ \\
Spleen & $7.13 \pm 0.90$ & $3.09 \pm 0.35$ & $1.74 \pm 0.36$ \\
Liver & $26.0 \pm 3.98$ & $14.5 \pm 3.15$ & $6.43 \pm 1.28$ \\
Brain & $0.87 \pm 0.14$ & $0.20 \pm 0.01$ & $0.12 \pm 0.01$ \\
Bone & $1.65 \pm 0.31$ & $0.89 \pm 0.16$ & $0.51 \pm 0.03$ \\
Tumor & $0.52 \pm 0.14$ & $1.55 \pm 0.10$ & $1.19 \pm 0.25$ \\
T:M ratio & 0.92 & 2.92 & 3.30 \\
\hline
\end{tabular}


Figure 1. Structures, binding affinities for $\sigma$ receptors, and $\log P$ of benzamide analogues

Figure 2. Chemical Structures of novel tetrahydroisoquinoline delivatives

Figure 3. Cellular Uptake and Blocking Study of $\left[{ }^{18} \mathrm{~F}\right] 7$ in EMT-6 Cells; black circle:Cell uptake of $\left[{ }^{18} \mathrm{~F}\right] 7$, gray square: Cell uptake of $\left[{ }^{18} \mathrm{~F}\right] 7$ in the presenceof $100 \mu \mathrm{M}$ RHM-4.

Figure 4. MicroPET images of EMT-6 tumors in female Balb/c mice. All microPET images were summed over the $2 \mathrm{~h}$ acquisition period after i.v. injection of either $\left[{ }^{18} \mathrm{~F}\right] 3$ (left panel) and $\left[{ }^{18} \mathrm{~F}\right] 7$ (right panel).

Figure 5. Time-activity curves and tumor to muscle ratios of $\left[{ }^{18} \mathrm{~F}\right] 3$ (left panel) and $\left[{ }^{18} \mathrm{~F}\right] 7$ (right panel) from microPET images studies; left top (tumor and muscle uptake of $\left[{ }^{18} \mathrm{~F}\right] 3$ ), left bottom (tumor/muscle ratio of $\left[{ }^{18} \mathrm{~F}\right] 3$, right top (tumor and muscle uptake of $\left[{ }^{18} \mathrm{~F}\right] 7$ ), and right bottom (tumor/muscle ratio of $\left[{ }^{18} \mathrm{~F}\right] 7$ ). 
Scheme 1. Reagents and conditions: a) $N$-(bromoalkyl)phthalimide, $\mathrm{K}_{2} \mathrm{CO}_{3}, \mathrm{CH}_{3} \mathrm{CN}, 120{ }^{\circ} \mathrm{C}, 20$ h; b) hydrazine monohydrate, EtOH, $70{ }^{\circ} \mathrm{C}, 3 \mathrm{~h}$; c) 2-fluoroethyl 4-methylbenzenesulfonate, $\mathrm{K}_{2} \mathrm{CO}_{3}, \quad \mathrm{CH}_{3} \mathrm{CN}, \quad 120{ }^{\circ} \mathrm{C}, 3 \mathrm{~h} ;$ d) $\mathrm{NaOH}, \quad \mathrm{H}_{2} \mathrm{O}, \quad \mathrm{MeOH}, 70{ }^{\circ} \mathrm{C}, \quad 3 \mathrm{~h} ;$ e) $N, N^{\prime}-$ dicyclohexylcarbodiimide (DCC), hydroxybenzotriazole ( $\mathrm{HOBt}$ ), $\mathrm{CH}_{2} \mathrm{Cl}_{2}$, room temperature, 20 h.

Scheme 2. Reagents and conditions: a) 2-fluoroethyl 4-methylbenzenesulfonate, $\mathrm{K}_{2} \mathrm{CO}_{3}, \mathrm{CH}_{3} \mathrm{CN}$, $120{ }^{\circ} \mathrm{C}, 3 \mathrm{~h}$; b) $\mathrm{NaOH}, \mathrm{H}_{2} \mathrm{O}, \mathrm{MeOH}, 70{ }^{\circ} \mathrm{C}, 3 \mathrm{~h}$; c) methyl thioglycolate, $\mathrm{NaH}$, DMSO, room temperature, $5 \mathrm{~min}$; d) methyl thioglycolate, $\mathrm{K}_{2} \mathrm{CO}_{3}$, DMF, $80{ }^{\circ} \mathrm{C}, 20 \mathrm{~h}$.

Scheme 3. Reagents and conditions: a) DCC, $\mathrm{HOBt}, \mathrm{CH}_{2} \mathrm{Cl}_{2}$, room temperature, $20 \mathrm{~h}$.

Scheme 4. Reagents and conditions: a) 2-bromoethyl acetate, $\mathrm{K}_{2} \mathrm{CO}_{3}, \mathrm{CH}_{3} \mathrm{CN}, 80{ }^{\circ} \mathrm{C}, 48 \mathrm{~h}$; b) $\mathrm{NaOH}, \mathrm{H}_{2} \mathrm{O}, \mathrm{MeOH}, 70{ }^{\circ} \mathrm{C}, 3 \mathrm{~h}$; c) $\mathrm{DCC}, \mathrm{HOBt}, \mathrm{CH}_{2} \mathrm{Cl}_{2}$, room temperature, $20 \mathrm{~h}$; d) methanesulfonyl chloride, $\mathrm{Et}_{3} \mathrm{~N}, \mathrm{CH}_{2} \mathrm{Cl}_{2}$, room temperarue, $3 \mathrm{~h}$; e) $\mathrm{K}_{222}, \mathrm{~K}^{18} \mathrm{~F}$, DMSO, $120{ }^{\circ} \mathrm{C}$, 15 min. 

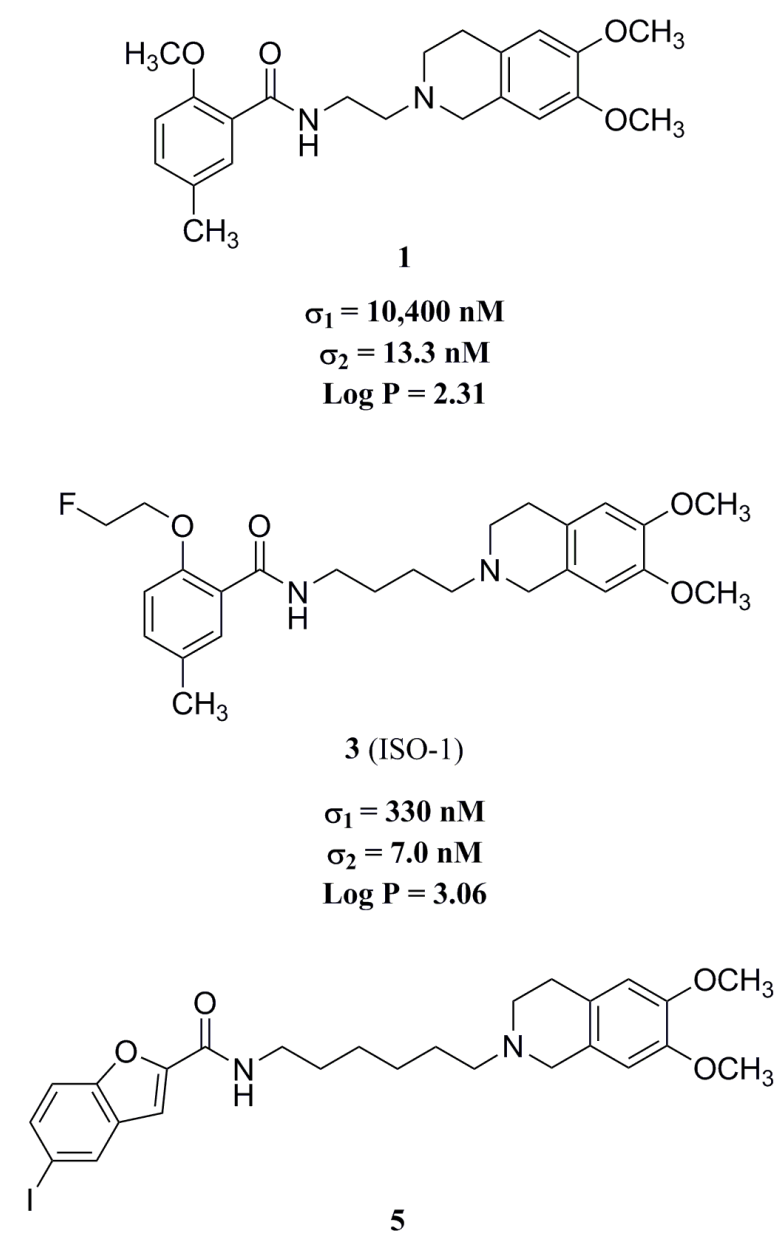

$\sigma_{1}=780 \mathrm{nM}$

$\sigma_{2}=0.88 \mathrm{nM}$

$\log P=4.47$

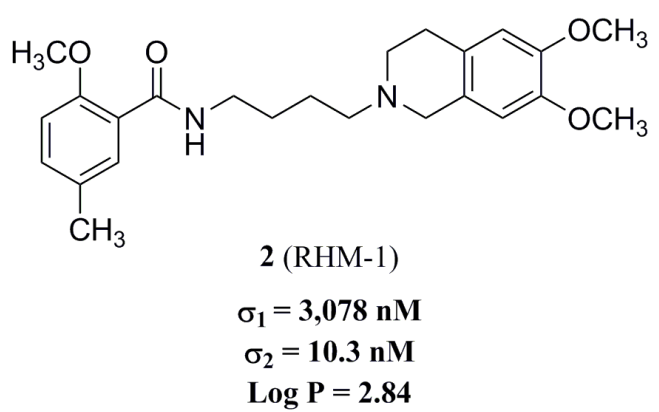<smiles>COc1cc2c(cc1OC)CN(CCCCNC(=O)c1cc(I)cc(OC)c1OCCF)CC2</smiles>

4 (FE-RHM-4)

$\sigma_{1}=2,150 \mathrm{nM}$

$\sigma_{2}=0.26 \mathrm{nM}$

$\log P=3.46$

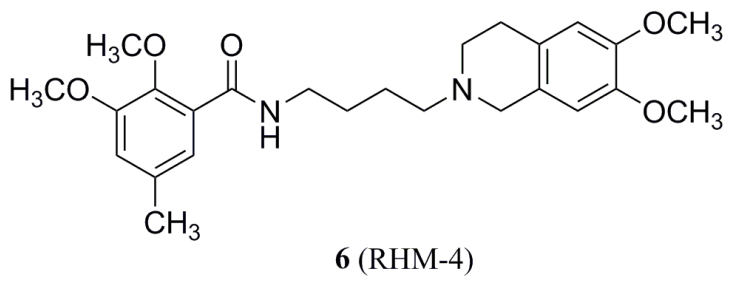

$K_{d}$ for $\sigma_{2}=0.68 \mathrm{nM}$ 

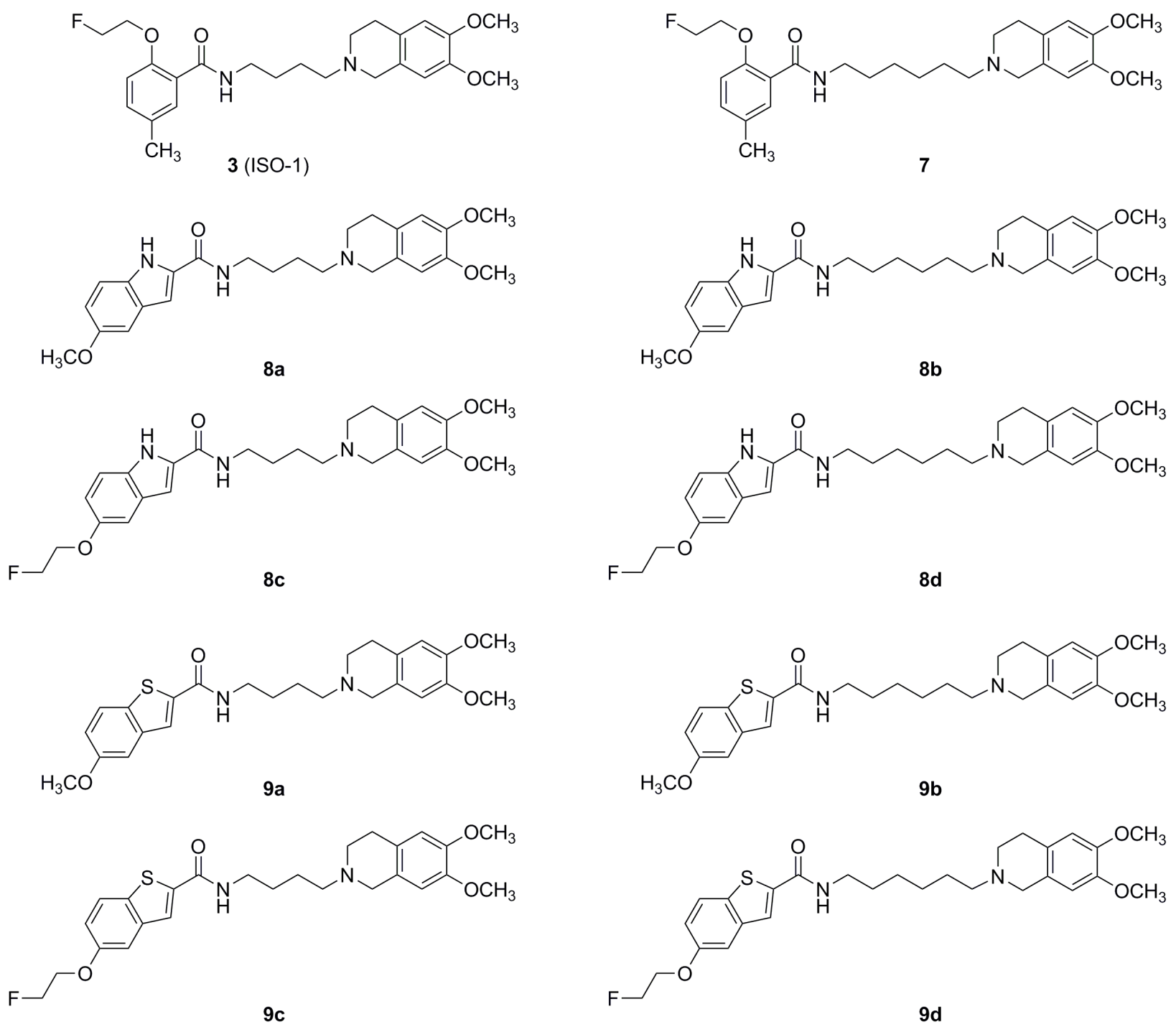


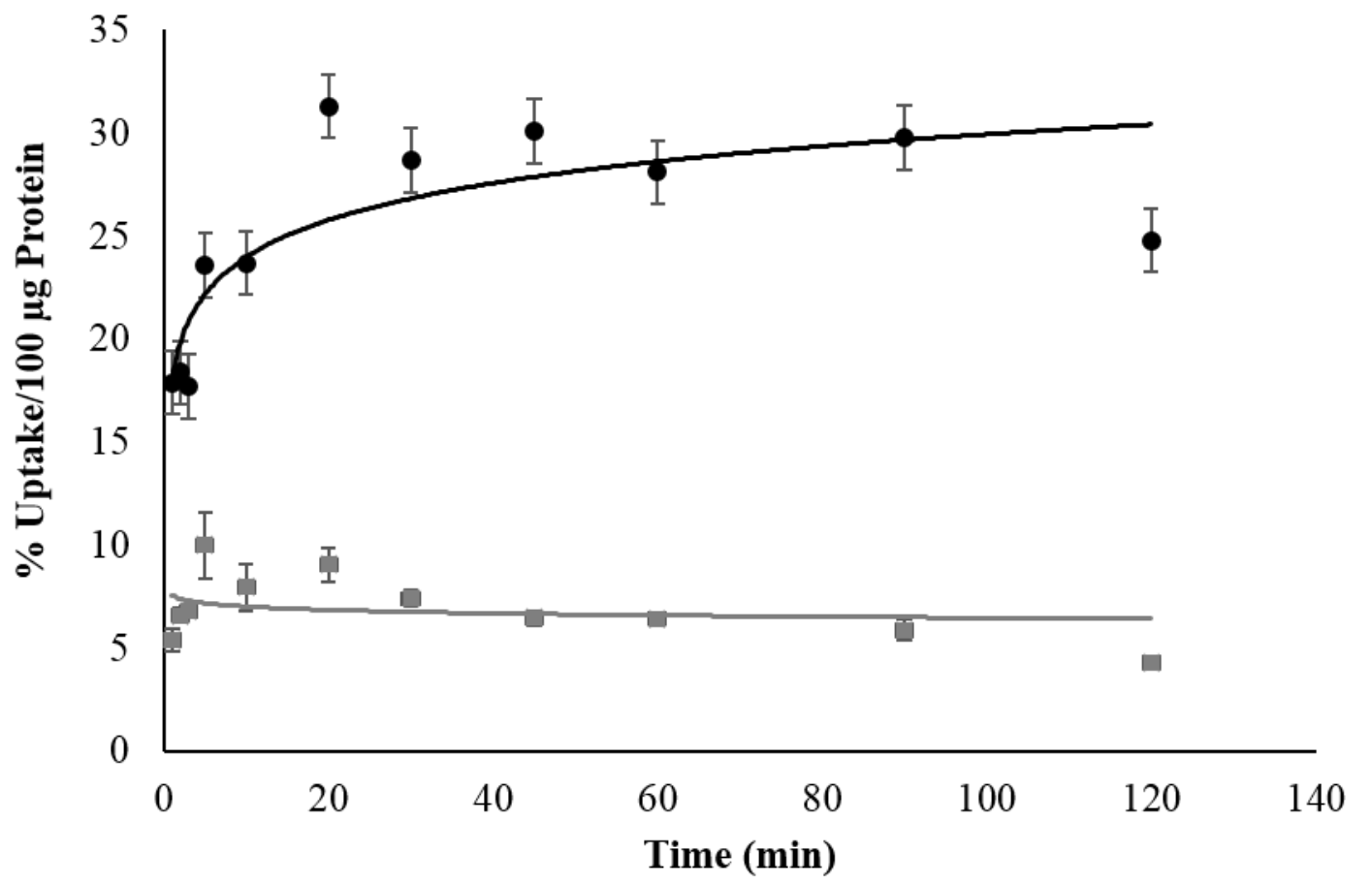




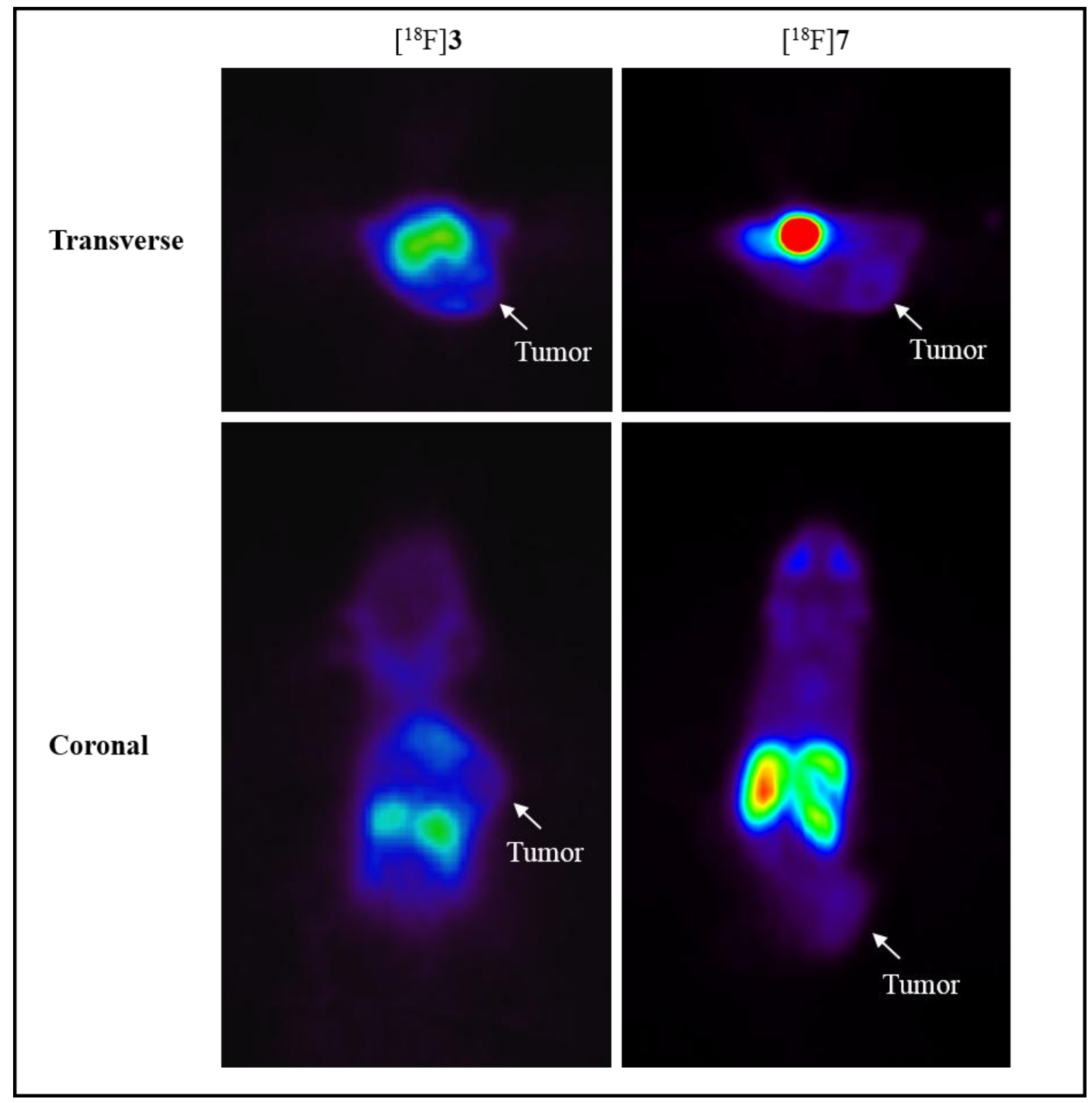




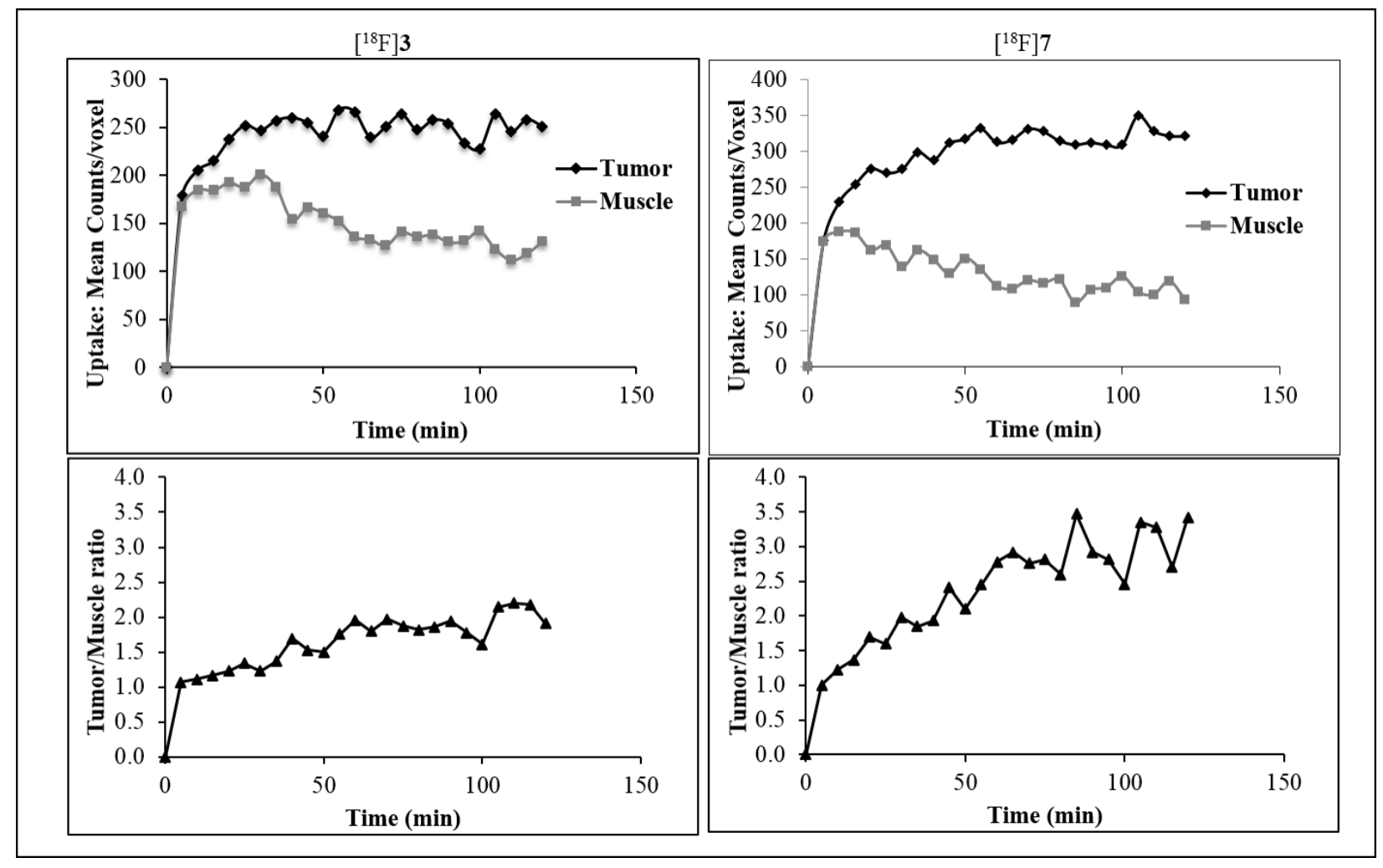

